\title{
Type 2 diabetes mellitus and the cardiometabolic syndrome: impact of incretin-based therapies
}

This article was published in the following Dove Press journal:

Diabetes, Metabolic Syndrome and Obesity:Targets and Therapy 8 July 2010

Number of times this article has been viewed

\author{
Stanley Schwartz' \\ Benjamin $\mathrm{A} \mathrm{Kohl}^{2}$ \\ 'Department of Endocrinology, \\ Diabetes, and Metabolism, University \\ of Pennsylvania, Philadelphia, \\ Pennsylvania, USA; ${ }^{2}$ Department of \\ Anesthesiology and Critical Care, \\ School of Medicine, University \\ of Pennsylvania, Philadelphia, \\ Pennsylvania, USA
}

\begin{abstract}
The rates of type 2 diabetes mellitus, obesity, and cardiovascular disease (CVD) continue to increase at epidemic proportions. It has become clear that these disease states are not independent but are frequently interrelated. By addressing conditions such as obesity, insulin resistance, stress hyperglycemia, impaired glucose tolerance, and diabetes mellitus, with its micro- and macrovascular complications, a specific treatment strategy can be developed. These conditions can be addressed by early identification of patients at high risk for type 2 diabetes, prompt and aggressive treatment of their hyperglycemia, recognition of the pleiotropic and synergistic benefits of certain antidiabetes agents on CVD, and thus, avoiding potential complications including hypoglycemia and weight gain. Incretin-based therapies, which include glucagon-like peptide-1 (GLP-1) receptor agonists and dipeptidyl peptidase-IV (DPP-IV) inhibitors, have the potential to alter the course of type 2 diabetes and associated CVD complications. Advantages of these therapies include glucose-dependent enhancement of insulin secretion, infrequent instances of hypoglycemia, weight loss with GLP-1 receptor agonists, weight maintenance with DPP-IV inhibitors, decreased blood pressure, improvements in dyslipidemia, and potential beneficial effects on $\mathrm{CV}$ function.
\end{abstract}

Keywords: cardiovascular disease, glucose control, GLP-1 receptor agonists, DPP-IV inhibitors

\section{Introduction}

Type 2 diabetes mellitus produces acute and chronic toxicity to vascular endothelium in patients as a result of exposure to postprandial glucose (PPG) spikes and continuous hyperglycemia. This culminates in the development of microvascular (eg, retinopathy, nephropathy, neuropathy) and macrovascular (eg, peripheral vascular disease, myocardial infarction [MI], stroke) complications. ${ }^{1}$

Damage to blood vessels starts early in the disease process, and as a result, patients often present with cardiovascular disease (CVD) and its associated complications before actually meeting the diagnostic criteria for type 2 diabetes. ${ }^{2-4}$ Hyperglycemia is a continuous risk factor, with no apparent glycated hemoglobin $\left(\mathrm{HbA}_{1 \mathrm{c}}\right)$ threshold above which complications begin. ${ }^{5,6}$ Because type 2 diabetes and CVD are so closely interrelated, treatment should focus on the shared pathophysiologic mechanisms of the 2 diseases.

This article will review the association between altered glucose metabolism, obesity, and $\mathrm{CV}$ risk. Current concepts on the pathophysiology of type 2 diabetes and proof of concept studies supporting future investigation into the benefits of incretin-based therapies on diabetes and CV outcomes will be discussed.
Correspondence: Stanley Schwartz Penn Presbyterian Medical Center, 2nd Floor, Philadelphia Heart Institute, 5I North 39th St, Philadelphia, PA 19104, USA

$\mathrm{Tel}+\mid$ 215-662-8099

Email stan.schwartz@uphs.upenn.edu 


\section{Altered glucose metabolism and CVD risk}

Clinical studies, including the San Antonio Heart Study, ${ }^{7}$ the West of Scotland Coronary Prevention Study, ${ }^{4}$ and the Heart Outcomes Prevention Evaluation (HOPE) Study, ${ }^{8}$ have shown the complex interplay between CVD, altered glucose metabolism, and obesity. The risk for CVD events (CVD-related mortality, MI, stroke) increases across quintiles of homeostasis model assessment of insulin resistance ${ }^{7}$; Sattar and colleagues $^{4}$ also demonstrated incrementally increased risk for CVD events (hazard ratio $[\mathrm{HR}]=1.76 ; 95 \%$ confidence interval [CI], 1.44-2.15) and diabetes $(\mathrm{HR}=3.50 ; 95 \% \mathrm{CI}$, 2.51-4.90) with each additional finding of components of the metabolic syndrome. Components of the metabolic syndrome included elevated triglycerides (TGs) $\geq 150 \mathrm{mg} / \mathrm{dL}$, lowered high-density lipoprotein cholesterol (HDL-C) $<40$ $\mathrm{mg} / \mathrm{dL}$, fasting glucose $\geq 110 \mathrm{mg} / \mathrm{dL}$, systolic blood pressure $(\mathrm{SBP}) \geq 130 \mathrm{~mm} \mathrm{Hg}$ or diastolic BP $(\mathrm{DBP}) \geq 85 \mathrm{~mm} \mathrm{Hg}$, and body mass index $(\mathrm{BMI})>28.8 \mathrm{~kg} / \mathrm{m}^{2}$. Increased waist-to-hip ratio and waist circumference all worsen the prognosis for men and women with CVD and highlight the importance of weight management in patients with $\mathrm{CV}$ risk. ${ }^{9}$

The Diabetes Epidemiology: Collaborative analysis of Diagnostic criteria in Europe (DECODE) ${ }^{3}$ and Whitehall ${ }^{2}$ studies have corroborated that the risk of CVD-related morbidity and mortality may start significantly before the diagnosis of type 2 diabetes. This finding has been reported in several studies. In the Cardiovascular Health Study, fasting glucose $\geq 115 \mathrm{mg} / \mathrm{dL}$ was associated with elevated CVD risk $(\mathrm{HR}=1.66 ; 95 \% \mathrm{CI}, 1.39-1.98) .{ }^{10}$ The Nurses' Health Study showed that risk for CVD began to increase $\geq 15$ years before diagnosis of diabetes (Figure 1). ${ }^{11}$ The Norfolk study (Figure 2) documented a steady increase in CV events corresponding to an $\mathrm{HbA}_{1 \mathrm{c}} \geq 5 \%$ in men and $\geq 6 \%$ in women $\left(P<0.001\right.$ for all). ${ }^{12}$ Haffner and colleagues ${ }^{13}$ reported that patients with diabetes, but with no prior MI, have the same risk for an MI as individuals without diabetes, who have had a prior MI. This suggests that CV risk factors in patients with diabetes need to be identified early and treated aggressively. ${ }^{13}$

In fact, multifactorial intervention aimed at controlling all CVD risk factors that may be present in a given patient is an important aspect of individualized treatment for patients with type 2 diabetes. The Steno- 2 study ${ }^{14}$ randomized 160 patients with type 2 diabetes, who also had persistent microalbuminuria to intensive multifactorial intervention (target $\mathrm{HbA}_{1 \mathrm{c}}<6.5 \%$ ) or conventional therapy. Intensive therapy in the Steno-2 study also had goals for fasting serum total cholesterol $<175 \mathrm{mg} / \mathrm{dL}$, fasting serum TG level $<150 \mathrm{mg} / \mathrm{dL}$, and BP $<130 / 80 \mathrm{~mm} \mathrm{Hg}$. Patients were treated with renin - angiotensin system blockers regardless of $\mathrm{BP}$ and received low-dose aspirin as primary prevention for CVD events. Patients in the Steno-2 study were followed for a mean of 7.8 years with subsequent follow-up for a mean of 5.5 years. The primary clinical end point for the Steno-2 study was "any cause" time to death at 13.3 years. Twentyfour patients in the intensive-therapy group died compared with 40 in the conventional-treatment group $(\mathrm{HR}=0.54$;

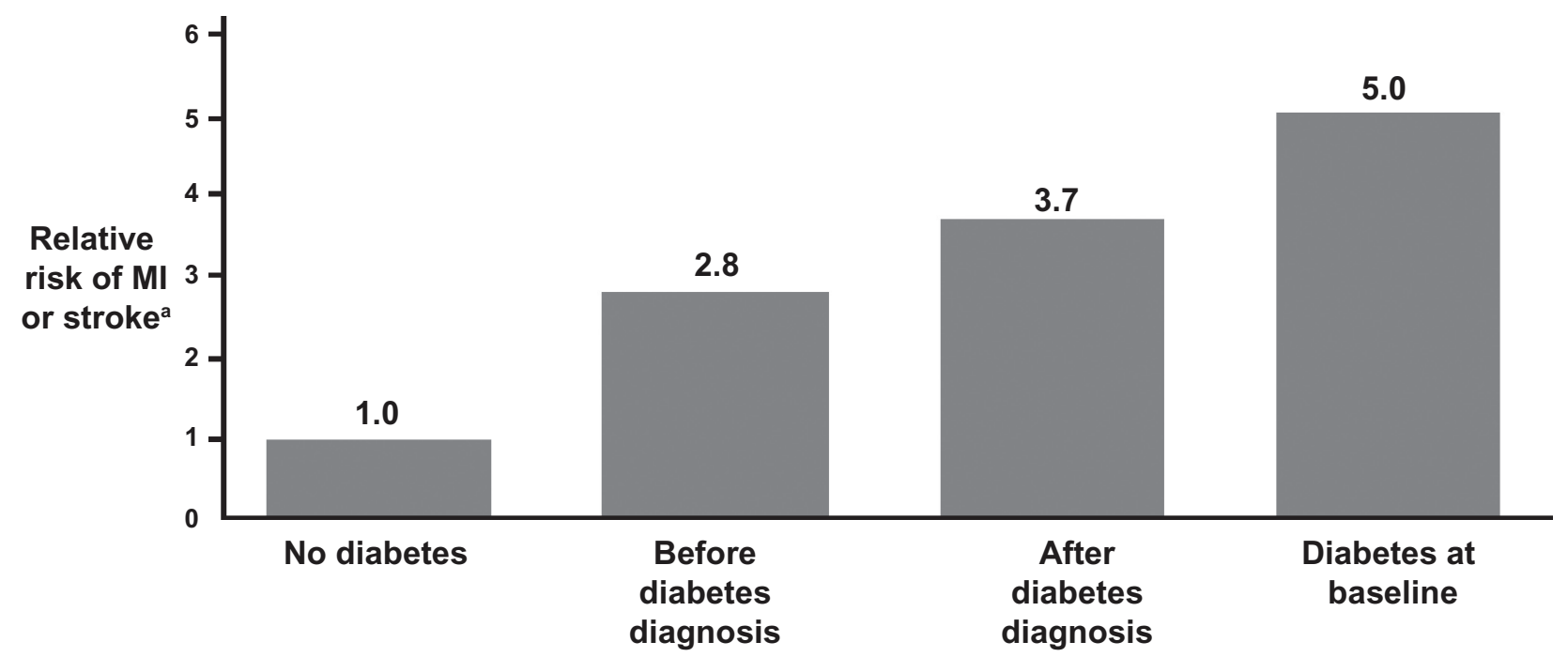

Figure I The "ticking clock" hypothesis. Glucose abnormalities increase cardiovascular risk even before the diagnosis of diabetes is made. Multivariate relative risks and $95 \%$ confidence intervals of myocardial infarction (MI) or stroke according to diabetes status. The Nurses' Health Study, N=1I7,629 women, aged 30-55 years; follow-up 20 years (1976-1996). Adapted with permission from Hu FB, Stampfer MJ, Haffner SM, Solomon CG, Willett WC, Manson JE. Elevated risk of cardiovascular disease prior to clinical diagnosis of type 2 diabetes. Diabetes Care. 2002;25(7): I 129-1 I34." Copyright (C) 2002 American Diabetes Association.

Note: ${ }^{a}$ Adjusted; $n=1,508$, diabetes at baseline; $n=5,894$, new-onset diabetes. 


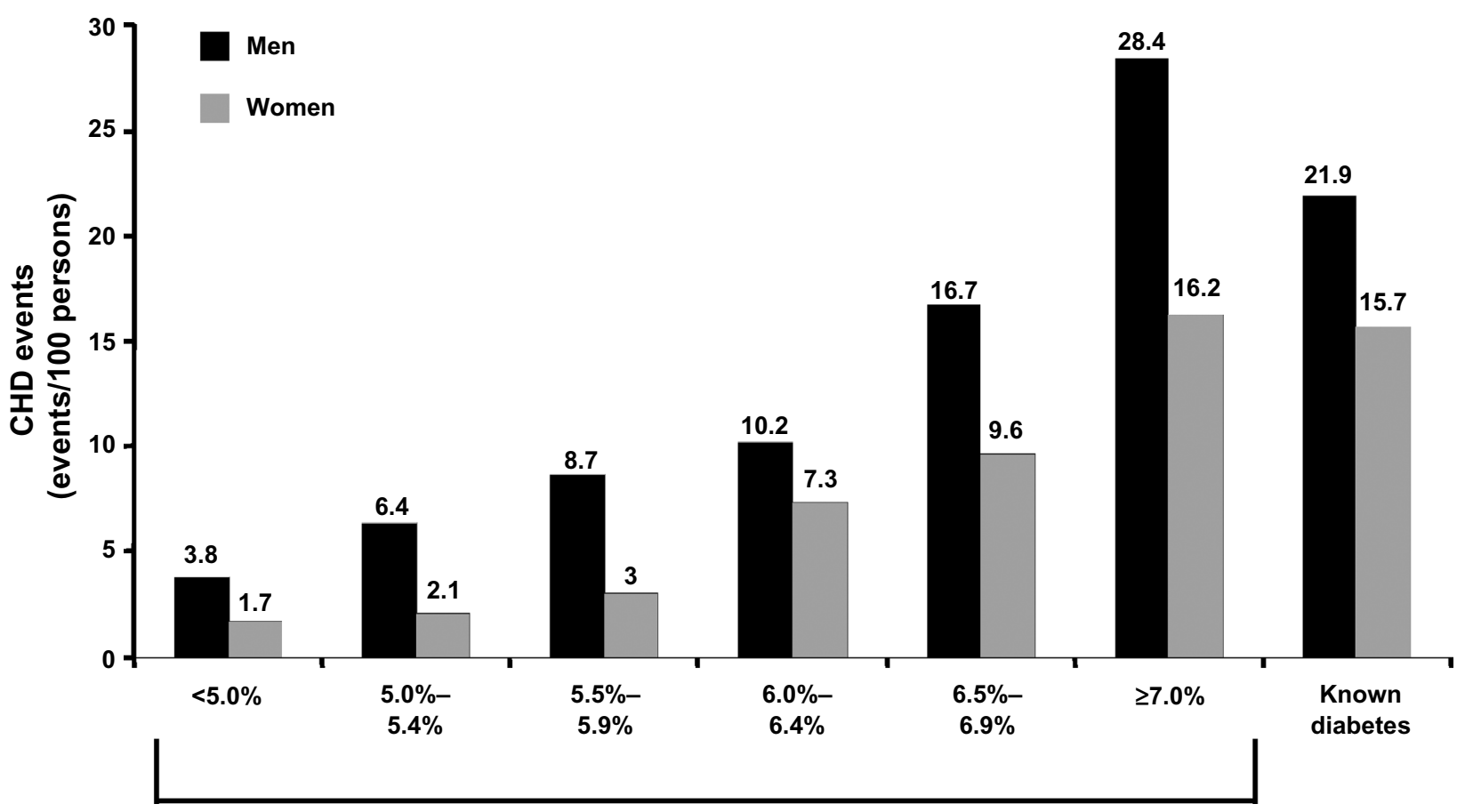

$\mathrm{HbA}_{1 \mathrm{c}}$ concentration ${ }^{\mathrm{a}}$

Figure 2 Glycated hemoglobin $\left(\mathrm{HbA}_{\mathrm{lc}}\right)$ and heart disease in type 2 diabetes. $\mathrm{HbA}_{\mathrm{lc}}$ predicts $\mathrm{CHD}$ in type 2 diabetes. Rates for total $\mathrm{CHD}$ events by category of HbA concentration and known diabetes in 4,462 men and 5,570 women aged 45-79 years. Adapted with permission from Khaw KT, Wareham N, Bingham S, Luben R, Welch A, Day N. Association of hemoglobin Alc with cardiovascular disease and mortality in adults: the European prospective investigation into cancer in Norfolk. Ann Intern Med. 2004; 14 I (6):413-420. ${ }^{2}$ Copyright (C) 2004 American College of Physicians.

Note: ${ }^{a}<<0.001$ for linear trend across $\mathrm{HbA}_{\mathrm{lc}}$ categories.

Abbreviation: CHD, coronary heart disease.

95\% CI, 0.32-0.89; $P=0.02)$. Intensive integrated treatment was also associated with a lower risk of death from CVD (HR $=0.43 ; 95 \%$ CI, 0.19-0.94; $P=0.04)$ and CVD events (HR $=0.41 ; 95 \% \mathrm{CI}, 0.25-0.67 ; P<0.001)$ versus conventional treatment. ${ }^{14}$ The results from the Steno- 2 study support the view that intensive integrated therapy in high-risk patients with type 2 diabetes has the potential to decrease the risk for both microvascular and macrovascular complications and mortality.

\section{Hospital inpatient considerations for glycemia and CVD}

The strong correlation between altered glucose metabolism/ hyperglycemia and CVD outcomes has also been reported in the critical care setting. ${ }^{15-17}$ Muhlestein et $\mathrm{al}^{16}$ showed that glucose abnormalities are prevalent in patients with coronary artery disease and that even mild glucose elevations are associated with an increased mortality in patients undergoing percutaneous coronary intervention. Mortality was increased $>3$-fold in patients with fasting glucose concentrations $>110 \mathrm{mg} / \mathrm{dL}$, underscoring the importance of early detection and treatment of hyperglycemia. ${ }^{16}$ A systematic overview found that blood glucose concentrations on hospital admission are an independent predictor of long-term morbidity and mortality in patients following an acute MI, regardless of diabetes mellitus status. Nondiabetic patients with glucose concentrations $\geq 6.1-8.0 \mathrm{mmol} / \mathrm{L}$ (Table 1 ; for converting $\mathrm{mmol} / \mathrm{L}$ units to $\mathrm{mg} / \mathrm{dL}$ units and vice versa in this article, see Table 1) had a 3.9-fold (95\% CI, 2.9-5.4) higher risk of mortality than similar individuals with lower

Table I Conversion table

\begin{tabular}{lll}
\hline & Convert $\mathbf{~ m m o l} / \mathbf{L}$ to $\mathbf{~} \mathbf{g} / \mathbf{d L}$ & Convert $\mathbf{~ m g} / \mathbf{d L}$ to $\mathbf{~ m m o l} / \mathbf{L}$ \\
\hline Blood glucose & Multiply by 18 & Divide by 18 or multiply by 0.055 \\
TC, LDL-C, HDL-C & Multiply by 38.67 & Divide by 38.67 or multiply by 0.025 \\
Triglycerides & Multiply by 88.57 & Divide by 88.57 or multiply by $0.01 \mathrm{I}$ \\
\hline
\end{tabular}

Abbreviations: TC, total cholesterol; LDL-C, low-density lipoprotein cholesterol; HDL-C, high-density lipoprotein cholesterol. 
glucose concentrations. ${ }^{15}$ In a prospective study of nondiabetic patients, $35 \%$ of patients admitted to a coronary care unit with acute MI developed impaired glucose tolerance (IGT) at discharge (95\% CI, 28-43) and 40\% had IGT (95\% CI, 32-48) 3 months later. The incidence of newly diagnosed diabetes in this population was 31\% (95\% CI, 24-38) and $25 \%$ (95\% CI, 18-32), respectively. These data suggest that fasting and postchallenge hyperglycemia might be used as early markers of individuals at high risk during the initial phase of an acute MI. ${ }^{17}$

The impact of intensive glycemic control on survival in critically ill, hospitalized patients remains unknown due to varied study results. ${ }^{18,19}$ In one study of hyperglycemic patients hospitalized for acute MI, glucose normalization postadmission was associated with lower mortality. This mortality benefit was noted whether or not the patients received insulin. ${ }^{18}$ However, in the Normoglycemia in Intensive Care Evaluation (NICE) and Survival Using Glucose Algorithm Regulation (SUGAR) Study, intensive glucose control increased mortality in patients in the intensive care unit (ICU). ${ }^{19}$ Patients ( $\mathrm{N}=6104$ ) who were expected to require treatment in the ICU for 3 or more consecutive days were randomized within 24 hours of admission to either intensive glucose control (target range, $81-108 \mathrm{mg} / \mathrm{dL}$ ) or conventional glucose control (target $\leq 180 \mathrm{mg} / \mathrm{dL}$ ). Death occurred in $27.5 \%$ of patients in the intensive control group and $24.9 \%$ in the conventional group (for intensive control, odds ratio $=1.14 ; 95 \% \mathrm{CI}, 1.02-1.28 ; P=0.02)$. Patients in the intensive group $(6.8 \%)$ reported more severe hypoglycemia (blood glucose $<40 \mathrm{mg} / \mathrm{dL}$ ) than patients in the conventional group $(0.5 \%, P<0.001)$. It remains unclear what effect hypoglycemia had on mortality in this study.

Any innovation that would afford intensive, inpatient control of glucose without undue hypoglycemia, including continuous intravascular glucose monitors, improved staff training in use of intensive protocols, and/or the use of experimentally validated treatment regimens, may improve outcomes in critically ill patients with hyperglycemia. ${ }^{20}$ Moreover, any pharmacologic therapy that could potentially reduce the need for antihyperglycemic agents that increase risk of hypoglycemia (ie, sulfonylureas [SFUs], glinides, insulin), when treating inpatients with stress/steroid-induced diabetes or pre-existing diabetes, should be investigated for its ability to reduce morbidity and mortality in this population.

\section{Aggressive glucose lowering}

Microvascular and $\mathrm{CV}$ risks increase in patients with a longer duration of diabetes and a higher $\mathrm{HbA}_{1 \mathrm{c}}$, with hyperglycemia being a continuous risk factor independent of $\mathrm{HbA}_{1 \mathrm{c}}$ level. ${ }^{5,21,22}$ Initiation of intensive therapy soon after diabetes is diagnosed reduced the risk of microvascular and macrovascular diseases, with additional benefits seen in patients with $\mathrm{HbA}_{1 \mathrm{c}}<$ $7 \% .^{6,21,23}$ Patients with a longer duration of diabetes and preexisting complications failed to show benefit with an $\mathrm{HbA}_{1 \mathrm{c}}$ of $\sim 7 \%$ in the Veterans Administration Diabetes Trial (VADT), ${ }^{24}$ an $\mathrm{HbA}_{1 \mathrm{c}}<6.5 \%$ in the Action in Diabetes and Vascular Disease: Preterax and Diamicron Modified Release Controlled Evaluation (ADVANCE) study, ${ }^{25}$ and in the Action to Control Cardiovascular Risk in Diabetes (ACCORD) study, ${ }^{26}$ with an actual increased rate of fatal MIs in ACCORD. However, a subgroup analysis showed a likely protective effect in patients with a shorter duration of diabetes or earlier atherosclerotic disease in $\mathrm{VADT}^{22}$ and reductions in $\mathrm{CV}$ outcomes in patients in ADVANCE without pre-existing microvascular or macrovascular disease and in patients in ACCORD without prior $\mathrm{CV}$ events (primary prevention) or baseline $\mathrm{HbA}_{1 \mathrm{c}}<$ $8 \%$. Moreover, in the ACCORD trial, it seems possible that unrecognized hypoglycemia and weight gain may have been major issues regarding its adverse outcomes. ${ }^{22}$ In addition, data from 2 meta-analyses that include the above studies, as well as the United Kingdom Prospective Diabetes Study $(\mathrm{UKPDS})^{23}$ and the PROspective pioglitAzone Clinical Trial In macroVascular Events (PROACTIVE) study, showed that lower glucose levels reduced MIs and CV events albeit with no effect on all-cause mortality. ${ }^{27,28}$

Currie et $\mathrm{al}^{29}$ published the results of a recent retrospective cohort study analyzing survival of patients with type 2 diabetes as a function of $\mathrm{HbA}_{1 \mathrm{c}}$. Two cohorts of patients with type 2 diabetes (age, 50 years and older) were analyzed from the United Kingdom General Practice Research Database from November 1986 to 2008 . The first cohort included 27,965 patients who had treatment intensified from oral monotherapy to combination oral therapy. The second cohort included 20,005 patients who had intensification with an insulin-containing regimen. The primary outcome was all-cause mortality. $\mathrm{HbA}_{1 \mathrm{c}}$ was broken out by deciles, and survival was analyzed as a function of $\mathrm{HbA}_{1 \mathrm{c}}$ decile. For the combined cohorts, compared with the $\mathrm{HbA}_{1 \mathrm{c}}$ decile with the lowest $\mathrm{HR}$ (median $\mathrm{HbA}_{1 \mathrm{c}}, 7.5 \%$; interquartile range [IQR], 7.5\%-7.6\%), the adjusted $\mathrm{HR}$ of allcause mortality in the lowest $\mathrm{HbA}_{1 \mathrm{c}}$ decile (median, 6.4\%; IQR, $6.1 \%-6.6 \%)$ was $1.52(95 \% \mathrm{CI}, 1.32-1.76)$ and in the highest $\mathrm{HbA}_{1 \mathrm{c}}$ decile (median, 10.5\%; IQR, 10.1\%-11.2\%) was 1.79 (95\% CI, 1.5-2.06). Results showed a U-shaped curve association, with the lowest HR at approximately $7.5 \%$.

In summary, low and high mean $\mathrm{HbA}_{1 \mathrm{c}}$ values were associated with increased all-cause mortality and cardiac events, 
and an $\mathrm{HbA}_{1 \mathrm{c}}$ value of approximately $7.5 \%$ was associated with the lowest all-cause mortality. ${ }^{29}$ Although these results lend support to the findings of ACCORD, the American Diabetes Association (ADA) and American Association of Clinical Endocrinologists (AACE) glycemic goals are still valid and clinicians should strive to reduce $\mathrm{HbA}_{1 \mathrm{c}}$ as low as possible for as long as possible, without causing undue hypoglycemia and weight gain. Figure 3 is a hypothetical representation of the natural history of diabetic subjects enrolled in CV outcome studies. ${ }^{30}$

These data highlight the importance of being able to balance the benefits and risks of medications when making treatment decisions using antidiabetes agents that minimize the risk of hypoglycemia and weight gain, and possibly even lead to weight loss.

The new AACE/American College of Endocrinology (ACE) guidelines ${ }^{31}$ emphasized this by recommending oral hypoglycemic agents (SFUs/glinides) last, if at all. Early use of incretins along with metformin (MET) and thiazolidinediones (TZDs) and early use of combination therapy are also recommended.

Thus, based on the pathophysiology of type 2 diabetes and its association with increased CVD risk, ${ }^{32}$ the current goals advocated by the ADA, the European Association for the Study of Diabetes, and the AACE are to achieve the lowest possible $\mathrm{HbA}_{1 \mathrm{c}}$ without undue risk of hypoglycemia and weight gain with appropriate individualization. In fact, the ADA has recognized this approach and is supporting a study comparing ${ }^{33}$ the biguanide, MET, the TZD, pioglitazone, and the glucagon-like peptide-1 (GLP-1) receptor agonist, exenatide, with treatment according to its own guidelines that advocate the use of SFUs or early insulin therapy after the failure of MET. ${ }^{34}$

\section{The role of incretins in the pathophysiology of type 2 diabetes}

Treatment of patients with type 2 diabetes has traditionally focused on improving reduced $\beta$-cell function, preventing increased peripheral insulin resistance/hepatic gluconeogenesis, as well as reducing the rate of absorption of nutrients from the gut. ${ }^{35}$ These issues have been addressed with various hypoglycemic and antidiabetic regimens including SFUs, MET, TZDs, and $\alpha$-glucosidase inhibitors. Unfortunately, treatment with some of these agents is associated with hypoglycemia, weight gain, increased CV risks, and other adverse events. ${ }^{36}$

It is now known that the pathophysiology of type 2 diabetes is much more complex than previously believed and that there are other important mechanisms involved in glucose metabolism. Nauck et a ${ }^{37}$ found differences in $\beta$-cell secretory

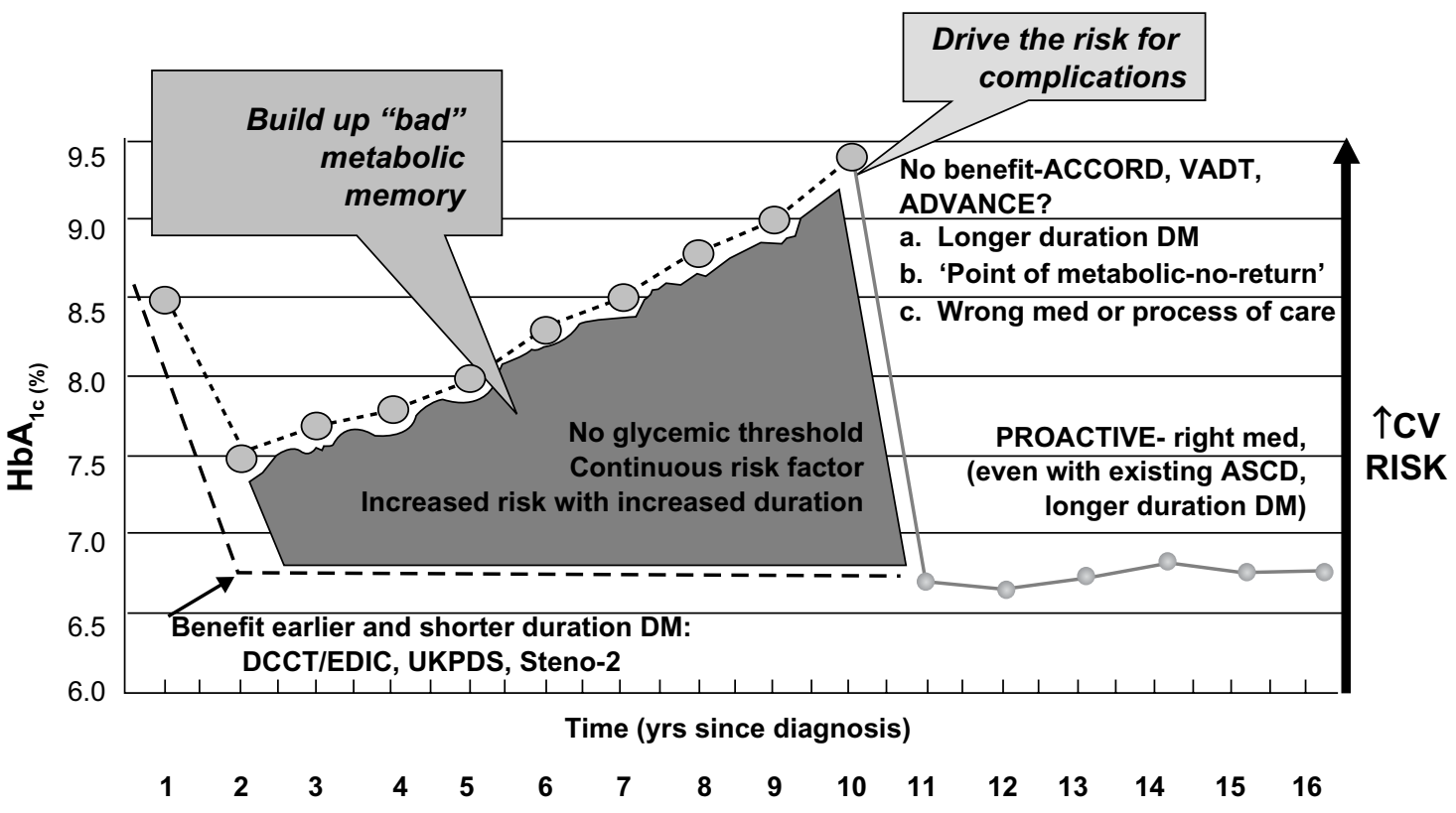

Figure 3 Understanding cardiovascular outcome studies in type 2 diabetes mellitus. These data highlight the importance of balancing the benefits and risks of antidiabetes medications when making treatment decisions using agents that minimize the risk of hypoglycemia and weight gain, and possibly lead to weight loss.

Note: So given epidemiology, pathophysiology, aim for $<6.0 \%$, start early, use right meds, without hypoglycemia and visceral weight gain. Adapted with permission from del Prato $\mathrm{S}$. Megatrials in type 2 diabetes. From excitement to frustration? Diabetologia. 2009;52(7):1219-1226. ${ }^{30}$ Copyright () 2009 Springer.

Abbreviations: ACCORD, Action to Control Cardiovascular Risk in Diabetes; ADVANCE, Action in Diabetes and Vascular Disease: Preterax and Diamicron MR Controlled Evaluation; ASCD, atherosclerotic cardiovascular disease; CV, cardiovascular; DCCT/EDIC, Diabetes Control and Complications Trial/Epidemiology of Diabetes Interventions and Complications; DM, diabetes mellitus; $\mathrm{HbA}_{I c}$, glycated hemoglobin; PROACTIVE, Prospective Pioglitazone Clinical Trial in Macrovascular Events; UKPDS, United Kingdom Prospective Diabetes Study; VADT, Veterans Affairs Diabetes Trial. 
responses between oral and intravenous glucose challenges that were attributable to factors other than glycemia (the incretin effect). The incretin-based pathway was found to account for $\sim 70 \%$ of the insulin response to orally ingested glucose. ${ }^{37,38}$ The key activities of this pathway occur primarily through the actions of 2 intestinal insulin-stimulating hormones: GLP-1 and glucose-dependent insulinotropic polypeptide (GIP). GLP-1 and GIP have various actions in the body, including slowing gastric motility, increasing satiety, improving glycemic control, and reducing postprandial fatty acids (Figure 4). ${ }^{39}$ For a variety of reasons, GLP-1 has been found to be more amenable to therapeutic manipulation than GIP (patients with type 2 diabetes are resistant to GIP administration) and, therefore, has been the focus of more intensive research. ${ }^{39,40}$

It has been suggested that a decreased GLP-1 response to food may contribute to the progression of type 2 diabetes. This was confirmed in a study which reported that meal-stimulated
GLP-1 response was decreased in patients with type 2 diabetes. The authors concluded that this response may contribute to the decreased incretin effect seen in patients with type 2 diabetes. ${ }^{41}$ Administration of GLP-1 was shown to increase both first- and second-phase insulin response, ${ }^{42}$ improve insulin secretion and inhibit glucagon secretion, ${ }^{43}$ and normalize glucose levels in patients with type 2 diabetes. ${ }^{44}$ In addition, GLP-1-mediated effects on insulin and glucagon levels in patients with type 2 diabetes are glucose-dependent, and exogenous administration of GLP-1 does not induce hypoglycemia. ${ }^{45}$

This characteristic may be a result of GLP-1's effect on the insulin secretion amplification pathway rather than on the direct triggering pathway. ${ }^{46-49}$ Figure 5 depicts the pathways for glucose-stimulated secretion of insulin. ${ }^{50}$

Preclinical studies suggest that there are several potential pathways of GLP-1-mediated protection of the $\beta$-cell, including direct effects on signaling cascades that induce

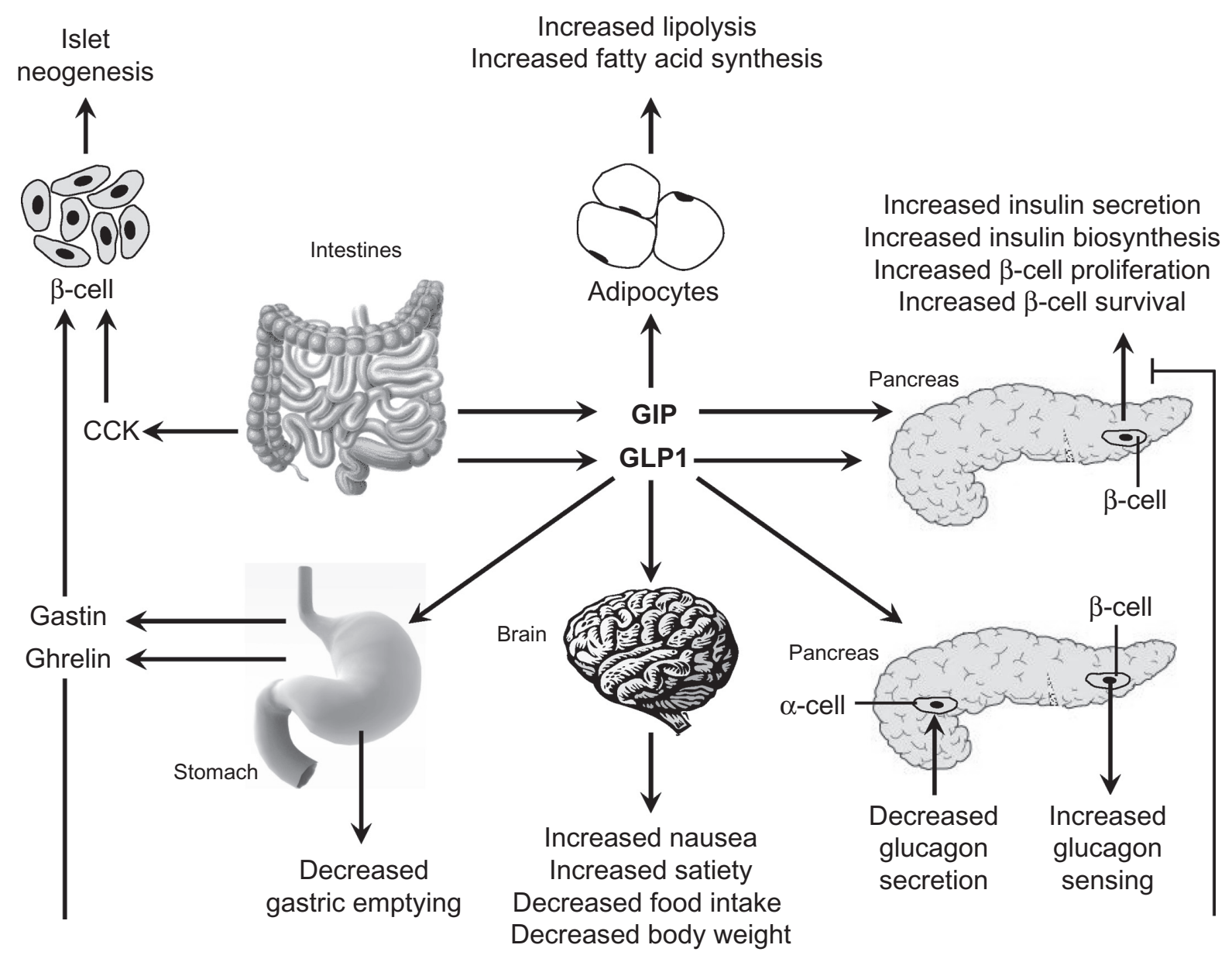

Figure 4 Actions of gastrointestinal hormones on key tissues in glucose homeostasis. Both GIP and GLP-I promote insulin biosynthesis, insulin secretion, and islet $\beta$-cell survival. GLP-I exerts additional actions, including inhibition of glucagon secretion and gastric emptying, and induction of food intake. GIP has a direct effect on adipocytes coupled to energy storage. In contrast, CCK and gastrin do not regulate plasma glucose levels but could be important for stimulation of islet neogenesis. Reprinted with permission from Girard J. The incretins: from the concept to their use in the treatment of type 2 diabetes. Part A: incretins: concept and physiological functions. Diabetes Metab. 2008;34(6 Pt I):550-559. ${ }^{39}$ Copyright (c) 2008 Elsevier.

Abbreviations: CCK, cholecystokinin; GIP, glucose-dependent insulinotropic polypeptide; GLP-I, glucagon-like peptide-I. 


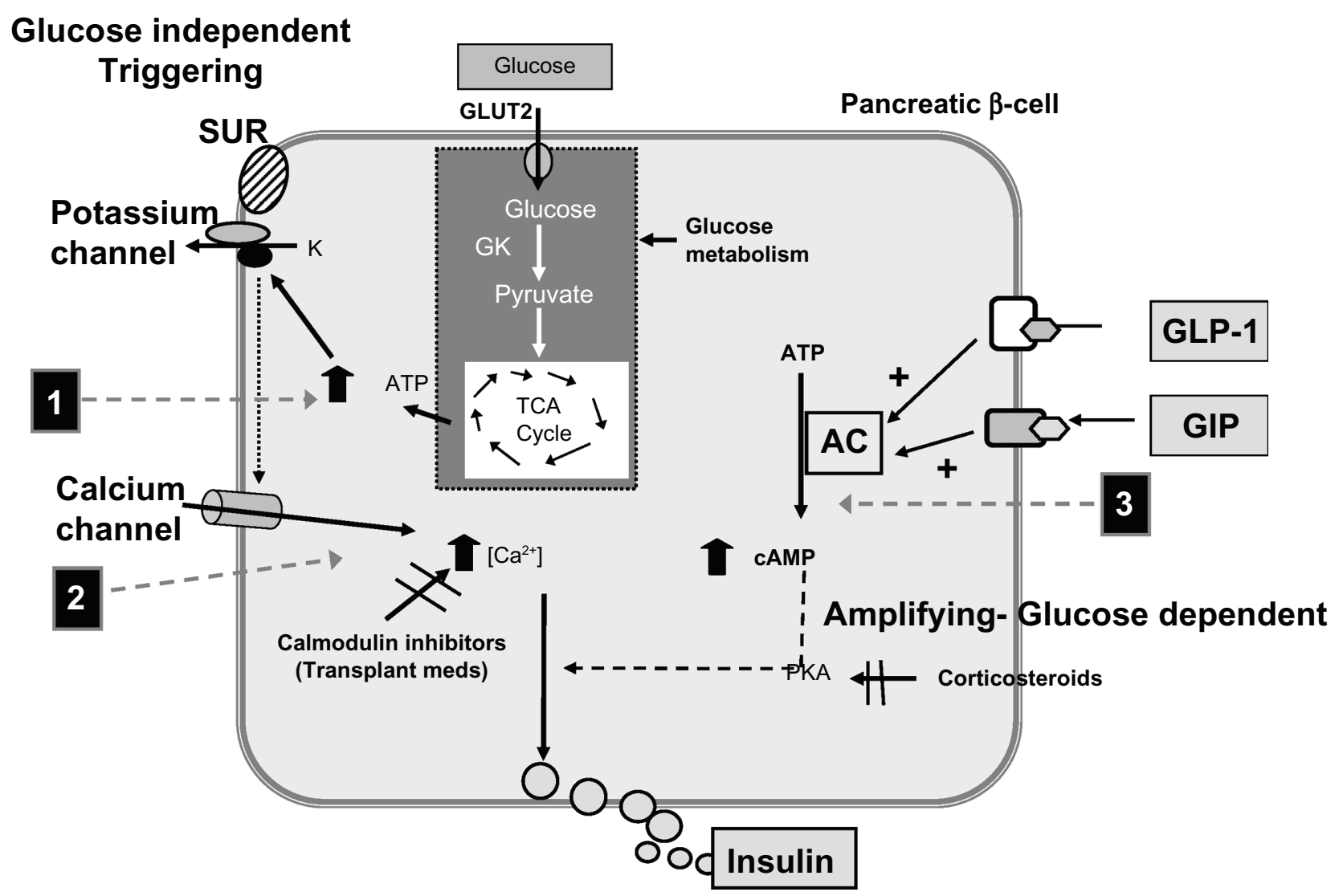

Figure 5 Glucose-stimulated secretion of insulin and potential mechanisms of interference by selected medications. Also, the potential mechanism by which GLP-I may overcome these hyperglycemic effects. Adapted with permission from Van Raalte DH, Ouwens DM, Diamant M. Novel insights into glucocorticoid-meidated diabetogenic effects: towards expansion of therapeutic options? Eur J Clin Invest. 2009;39(2):8I-93.50 Copyright @ 2009 John Wiley and Sons.

Abbreviations: AC, adenyl cyclase; ATP, adenosine triphosphate; cAMP, cyclic adenosine monophosphate; GIP, glucose-dependent insulinotropic polypeptide; GK, glucokinase; GLP-I, glucagon-like peptide-I; GLUT2, glucose transporter 2; PKA, protein kinase A; SUR, sulfonylurea receptor; TCA, tricaroboxylic acid (Kreb's cycle).

$\beta$-cell proliferation, increase pancreatic islet regeneration, and reduce $\beta$-cell apoptosis. These effects may be mediated by GLP-1's influence on the transcription factor pancreas duodenum homeobox-1 (PDX-1). ${ }^{51,52}$ PDX-1 expression has been found essential for integrating GLP-1 receptordependent signals, regulating $\alpha$-cell glucagon secretion, and for the growth, differentiated function, and survival of islet cells in mice. ${ }^{53}$ In addition, GLP-1 has been shown to counteract the negative effect of steroids on the $\beta$-cell secretion of insulin. This may be, in part, related to its effects on PDX-1 ${ }^{54}$ Glucocorticoids, such as dexamethasone, suppress pancreatic $\beta$-cell gene expression by interfering with islet-specific gene enhancers. Dexamethasone has also been shown to induce $\beta$-cell apoptosis in mouse models, an effect reversible with administration of synthetic GLP- $1 .{ }^{54}$

Moreover, GLP-1 seems to overcome steroids' acute negative effects, as well as transplant medication effects (eg, calmodulin inhibitors $)^{55}$ on the insulin amplifying pathway. ${ }^{56}$

In clinical trials, the effects of GLP-1 receptor agonists on $\beta$-cell function can be measured with surrogate markers of insulin secretion and/or homeostasis model assessment indices of $\beta$-cell function (HOMA-B). Beneficial effects of GLP-1 on pancreatic function have been documented in clinical studies. In 1 study, plasma glucose concentrations were significantly lowered during intravenous infusion of GLP-1 in 8 patients with type 2 diabetes and stress hyperglycemia following major surgery. Fasting glucose was in normal range within 150 minutes but remained elevated during placebo infusion $(P<0.001)$. GLP-1 infusion led to a significant increase in insulin secretion $(P<0.001)$ and suppression of glucagon secretion $(P=0.041)$, with no reports of hypoglycemic events. ${ }^{57}$ In addition, 1-year treatment with exenatide demonstrated improvement in glucose- and arginine-stimulated insulin secretion ${ }^{58}$ while 3 -year treatment showed sustained HOMA-B improvement. ${ }^{59}$

Limited data have demonstrated a potential benefit for the short-term use of intravenous GLP-1 to be effective in patients with stress-induced diabetes (eg, postoperative hyperglycemia), especially in patients with prediabetes, or in patients with type 2 diabetes that have been treated with prior 
oral hypoglycemic and antidiabetes therapies. By impacting the hyperglycemic effects of glucagon and steroids (2 stress hormones), GLP-1 (and agents with incretin effects such as the GLP-1 receptor agonists) may be leveraged to decrease the need for SFU, glinide, or insulin use in hospitalized patients, and therefore, the potential development of treatment-related hypoglycemia. ${ }^{60,61}$

\section{Additional actions and benefits of incretins}

The pharmacologic actions of GLP-1 extend well beyond the pancreas, as GLP-1 receptors have been found in smooth muscle cells, cardiac myocytes, endocardium, vascular endothelium, and hypothalamus. ${ }^{38,40,62}$ Improved CV status, including enhanced cardiomyocyte viability after ischemiareperfusion injury and increased systolic function in preclinical models, ${ }^{63}$ relaxation of rat conduit arteries, ${ }^{64}$ and peripheral vasodilation in healthy volunteers and patients with type 2 diabetes, ${ }^{63}$ and reduction of inflammatory markers ${ }^{63}$ have been demonstrated with GLP-1 administration.

A 72-hour infusion of GLP-1 added to standard therapy in acute MI patients with and without diabetes $(n=10)$ significantly improved left ventricular ejection fraction (LVEF) ( $29 \pm 2 \%$ to $39 \pm 2 \%, P<0.01)$ compared with controls $(\mathrm{n}=11)$ as measured by echocardiograms after reperfusion and after completion of GLP-1 administration. ${ }^{65} \mathrm{CV}$ benefits were also seen in patients with congestive heart failure after MI, who received 5 weeks of GLP-1 infusion $(n=12)$. These patients showed a significant improvement in LVEF regardless of diabetic status $(21 \%-27 \%, P<0.001)$ compared with no change in patients on standard therapy alone $(21 \%-22 \%) .{ }^{66}$ Infusion of GLP-1 peri-MI also improved regional functional recovery in the peri-infarct zone in humans $(n=10) .{ }^{65}$ Sokos et $\mathrm{al}^{67}$ investigated the effect of a continuous 48-hour infusion of GLP-1 beginning 12 hours before coronary artery bypass graft (CABG) surgery in 10 patients with coronary heart disease and preserved LV function. This resulted in a reduced need for vasopressors, reduced arrhythmias, and significantly better glycemic control in the pre- and perioperative periods ( $95 \mathrm{mg} / \mathrm{dL}$ vs $140 \mathrm{mg} / \mathrm{dL}, P \leq 0.02$ ), with $45 \%$ less insulin requirements to achieve the same level of glycemia as in controls $(n=10)$ in the postoperative period (139 mg/dL vs $140 \mathrm{mg} / \mathrm{dL}) .{ }^{67}$ Concurrent use of GLP-1 receptor agonists with insulin has not been studied and cannot be recommended; however, studies are needed to evaluate their efficacy and safety together.

Additional extrapancreatic effects of incretins have been reported..$^{38,40}$ The impact of GLP-1 on gastric emptying has been described earlier. The mechanisms responsible for the slowing of gastric emptying appear complex and may involve activation of signaling mechanisms in both central and peripheral nervous system. ${ }^{38,40}$ Similar mechanisms may be responsible for early satiety. Intracerebroventricular and peripheral administration of GLP-1 has been shown to inhibit food intake in rodents. The GLP-1 receptors affected have been localized to the hypothalamic nuclei. ${ }^{38,40}$ The ability of GLP-1 receptor agonists to produce weight loss has been well demonstrated in clinical trials. ${ }^{59}$ Additional effects of GLP-1 have been reported on the nervous system (antiapoptotic effect on neuronal cells), the renal system (natriuresis), and the hypothalamic-pituitary axis, but the clinical significance of these effects remain undetermined. ${ }^{38}$

\section{The impact of incretin-based therapies on CVD-related risk factors}

Attempts to limit the use of GLP-1 as a therapeutic agent in the treatment of type 2 diabetes have advanced in recent years. One of the major barriers to the potential use of GLP-1 therapy is its short half-life in the circulation, ${ }^{41}$ which is due largely to its inactivation by the enzyme dipeptidyl peptidase-IV (DPP-IV). ${ }^{40}$ Although GLP-1 is rapidly released in response to oral glucose from L cells in the gut, it has a half-life of only $\sim 2$ minutes in the circulation and thus contributes to the first-phase insulin response. ${ }^{68}$ These findings led to the development of incretin mimetics, such as GLP-1 receptor agonists that are resistant to DPP-IV degradation, and DPP-IV inhibitors, which inhibit the proteolytic cleavage and inactivation of GLP-1. ${ }^{40,41}$ DPP-IV inhibitors increase the concentration of endogenous GLP-1 by $\sim 2$-fold.

\section{GLP-I receptor agonists}

Exenatide was the first incretin mimetic approved by the US Food and Drug Administration (FDA). It is a synthetic version of the naturally occurring salivary protein of the Gila monster, exendin- 4 , which has a $53 \%$ sequence identity to human GLP-1, is resistant to DPP-IV degradation, and demonstrates in vivo binding to human $\beta$-cell GLP-1 receptors. ${ }^{40,69}$ Exenatide is indicated as an adjunct to diet and exercise to improve glycemic control in adults with type 2 diabetes. Exenatide can be used as monotherapy or in combination with MET, SFU, and/or TZD and is administered twice-a-day by subcutaneous injection. Concurrent use of exenatide with insulin has not been studied and therefore cannot be recommended. ${ }^{70}$

Data from 30-week studies conducted in 963 patients with type 2 diabetes and inadequate glycemic control with SFU, 
MET, and combinations of these agents demonstrated that the addition of 5 and $10 \mu \mathrm{g}$ of exenatide was associated with significant decreases of $-0.60 \%$ and $-0.86 \%$, respectively, from baseline $\mathrm{HbA}_{1 \mathrm{c}}(P<0.002$ for all $) .{ }^{71-73}$ Patients treated with exenatide also showed progressive, dose-dependent weight loss of $-1.6 \mathrm{~kg}(5 \mu \mathrm{g})$ and $-2.8 \mathrm{~kg}(10 \mu \mathrm{g})(P<0.01$ vs placebo). ${ }^{71-73}$ Exenatide-treated patients were more likely to achieve a $\mathrm{HbA}_{1 \mathrm{c}} \leq 7 \%(5 \mu \mathrm{g}$ [27\%] and $10 \mu \mathrm{g}$ [34\%]) than placebo-treated patients $(9 \%, P<0.0001) .{ }^{73}$ The most frequently reported adverse events in these studies were generally mild or moderate and gastrointestinal in nature; no severe hypoglycemia was observed. ${ }^{71-73}$

The glucose- and weight-reducing effects of exenatide in 217 patients previously treated with SFU and/or MET have been sustained for up to 3 years. Initial reductions in $\mathrm{HbA}_{1 \mathrm{c}}$ from baseline to week $30(-0.9 \%)$ were sustained to week $82(-1.1 \%)^{74}$ and to 3 years $(-1.0 \%, P<0.0001)^{59} ; 48 \%$ of patients treated with exenatide achieved $\mathrm{HbA}_{1 \mathrm{c}} \leq 7 \%$ at week 82 and $46 \%$ at 3 years. ${ }^{59,74}$ Exenatide reduced body weight from baseline $(-2.1 \mathrm{~kg})$ after 30 weeks of treatment, with continued reductions observed at week $82(-4.4 \mathrm{~kg})^{74}$ and at 3 years $(-5.3 \mathrm{~kg}, P<0.0001){ }^{59}$

Data from a number of studies have shown that the addition of exenatide or insulin glargine or aspart to patients with type 2 diabetes and poor glycemic control on SFUs and MET is associated with similar reductions in $\mathrm{HbA}_{1 \mathrm{c}}$ (up to $-1.36 \%$ ). However, patients gained up to $+1.8 \mathrm{~kg}$ of weight after the addition of insulin but lost up to $-2.3 \mathrm{~kg}$ of weight with exenatide. ${ }^{75-77}$ Exenatide was also associated with fewer instances of hypoglycemia than insulin glargine or aspart. ${ }^{75-77}$ Thus, for the same degree of glycemic control, exenatide was associated with less hypoglycemia.

Treatment with exenatide was also associated with beneficial effects on other components of CVD risk, including dyslipidemia and elevated BP. After 3.5 years of exenatide treatment, 217 patients with type 2 diabetes demonstrated a $12 \%$ reduction in $\mathrm{TG}(-44.4 \mathrm{mg} / \mathrm{dL}), 5 \%$ in total cholesterol $(-10.8 \mathrm{mg} / \mathrm{dL}), 6 \%$ in low-density lipoprotein cholesterol $(-11.8 \mathrm{mg} / \mathrm{dL})$, and a $24 \%$ increase in HDL-C $(8.5 \mathrm{mg} / \mathrm{dL})$ from baseline. In addition, both SBP $(-3.5 \mathrm{~mm} \mathrm{Hg})$ and DBP $(-3.3 \mathrm{~mm} \mathrm{Hg})$ were reduced from baseline values. ${ }^{59}$

Exenatide has also produced significant improvements in $\mathrm{CV}$ risk factors, inflammatory cytokines, postprandial oxidative stress, and anthropomorphic parameters in patients with metabolic syndrome without type 2 diabetes. ${ }^{78-81}$ A meta-analysis of patients in the exenatide database showed an unadjusted incidence of experiencing $\geq 1 \mathrm{CV}$ event was $2.0 \%$ for exenatide and $2.6 \%$ for controls (relative risk $=0.69$;
95\% CI, 0.46-1.04). ${ }^{82}$ Assuming that the apparent reduction in $\mathrm{CV}$ outcomes is significant and reproducible, it has been estimated that use of exenatide over a 10-year period of time should result in a $50 \%$ decrease in the cumulative incidence of MI compared with MET and/or SFUs. ${ }^{83}$

Transient nausea has been reported in patients treated with exenatide in clinical trials. Practicing clinicians have learned many techniques to prevent or minimize the risk of nausea. One study ${ }^{84}$ showed that gradual dose escalation successfully reduced the proportion of patients experiencing dose-limiting nausea and vomiting without compromising glycemic control. In the authors' experience, patients should inject exenatide with their first bite of food and stop eating when they feel full. If patients continue to eat despite fullness, they may develop bloating and gastrointestinal upset, with eventual nausea and vomiting. These effects are presumably due to the slowing of gastric emptying seen with exenatide. ${ }^{85}$ Titration of exenatide to a dose of $10 \mu \mathrm{g}$ can occur after 1 month of therapy based on clinical response. Patients can delay eating up to 1 hour after administration but should take the drug with the first bite of a meal to reduce the risk of gastrointestinal upset. Patients are likely to lose their appetite between meals because of exenatide's hypothalamic effects to suppress appetite. ${ }^{40}$ This sensation very infrequently develops into nausea, which is usually mild in nature, and resolves within 2 weeks. Occasionally, the nausea can become intolerable, which accounts for the withdrawal of $3 \%$ of patients from clinical studies because of nausea and $1 \%$ because of vomiting. ${ }^{70}$

Rare cases of pancreatitis have been reported in patients treated with exenatide including fatal and nonfatal hemorrhagic or necrotizing pancreatitis. Exenatide postmarketing surveillance data are not sufficient to establish a drugrelated causality. Recent reviews have not documented an increased risk of pancreatitis with exenatide compared with other antidiabetes agents. ${ }^{86,87}$ However, until more data become available, treatment with exenatide should not be started in patients with a history of pancreatitis and should be discontinued in patients who exhibit symptoms of acute pancreatitis. If pancreatitis is confirmed, exenatide should not be restarted. ${ }^{70}$

There have been postmarketing reports of altered renal function, including increased serum creatinine, renal impairment, worsened chronic renal failure, and acute renal failure, sometimes requiring hemodialysis or kidney transplantation. Reversibility of altered renal function has been observed in many cases with supportive treatment and 
discontinuation of the potentially causative agents, including exenatide. Exenatide has not been shown to be nephrotoxic in preclinical or clinical studies. Exenatide should not be used in patients with severe renal impairment (creatinine clearance $<30 \mathrm{~mL} / \mathrm{min}) .^{70}$

Many patients are nervous about getting a subcutaneous injection. This fear is often inadvertently instilled by physicians and can often be alleviated through proper education in the office.

An extended-release formulation of exenatide, dosed once weekly, has been submitted to the US FDA for regulatory review. Treatment with exenatide once weekly has been associated with improved $\mathrm{HbA}_{1 \mathrm{c}}$, $\mathrm{BP}$, and lipid levels in patients with type 2 diabetes. ${ }^{88,89}$ After 30 weeks of treatment, exenatide once weekly produced significantly greater changes in $\mathrm{HbA}_{1 \mathrm{c}}$ than exenatide BID $(-1.9 \%$ vs $-1.5 \%$, $P=0.0023)$, with a significantly greater proportion of patients achieving target $\mathrm{HbA}_{1 \mathrm{c}} \leq 7 \%(77 \%$ with exenatide once weekly vs $61 \%$ with exenatide BID, $P=0.0039) .{ }^{89}$ One year of treatment with exenatide once weekly resulted in improvements in $\mathrm{HbA}_{1 \mathrm{c}}(-2.0 \%)$, weight $(-4.1 \mathrm{~kg})$, and SBP and DBP (6.2 $\mathrm{mm} \mathrm{Hg}$ and $2.8 \mathrm{~mm} \mathrm{Hg}$, respectively from baseline; $P<0.05) .{ }^{88}$ Exenatide once weekly is associated with a reduced risk for nausea.

Reductions in fasting blood glucose and PPG with the first treatment injection could make exenatide once weekly an ideal therapy to administer to patients prior to hospital admission (ie, for surgery), to treat stress hyperglycemia with likely improved glycemic control and a decrease in in-hospital hypoglycemia. Because of its extended effects on blood glucose levels, exenatide once weekly should be investigated for its ability to treat patients prior to hospital admission.

Liraglutide, another GLP-1 receptor agonist, is 97\% homologous to GLP-1 with an acyl moiety that promotes noncovalent binding to albumin. This reduces its degradation by DPP-IV, prolongs its half-life to $\sim 13$ hours, and allows for once-daily administration. ${ }^{69,90,91}$ Liraglutide has been approved for use as an adjunct to diet and exercise to improve glycemic control in adults with type 2 diabetes. It is not recommended as first-line therapy for patients inadequately controlled with diet and exercise. It can be used as monotherapy or in combination with MET, a SFU, or a TZD. The concurrent use of liraglutide and insulin has not been studied..$^{92}$ Liraglutide has also been approved in the European Union for adjunctive use in patients with type 2 diabetes and inadequate glycemic control with MET, SFU, MET and SFU, or MET and TZD combination therapy. Liraglutide is administered once daily via subcutaneous injection. ${ }^{92}$ In the Liraglutide Effect and Action in Diabetes (LEAD) studies, treatment with liraglutide (doses up to $1.8 \mathrm{mg}$ ) was associated with equivalent or greater improvements in $\mathrm{HbA}_{1 \mathrm{c}}$ and weight than comparator treatments including MET, combination of MET and SFU or TZD, and combination of MET, SFU, and insulin glargine. ${ }^{90,93-97}$ The LEAD studies also showed that liraglutide was associated with improvements in SBP and DBP. ${ }^{96,98-101}$

In clinical trials, liraglutide therapy has been associated with pancreatitis. Eight cases were reported during intermediate- and long-term trials in the liraglutide clinical development program. Seven of the cases were in patients treated with liraglutide and 1 case in a patient receiving a comparator. Of the 7 cases in liraglutide-treated patients, 5 were reported as acute pancreatitis and 2 were reported as chronic pancreatitis. There is no conclusive data establishing a risk of pancreatitis with liraglutide. After initiation of liraglutide, and after dose increases, clinicians should observe patients carefully for signs and symptoms of pancreatitis. If pancreatitis is suspected, liraglutide and other potentially suspect agents should be discontinued. If pancreatitis is confirmed, liraglutide should not be restarted. ${ }^{92}$

Liraglutide has a "box" warning in its full prescribing information for the risk of thyroid C-cell tumors in humans. The warning is as follows: liraglutide causes thyroid C-cell tumors at clinically relevant exposures in rodents. It is unknown whether liraglutide causes thyroid C-cell tumors, including medullary thyroid carcinoma (MTC), in humans as human relevance could not be determined by clinical or nonclinical studies. ${ }^{92}$ The basis for this warning arises from carcinogenicity studies that showed proliferative changes in the C-cells of the thyroid gland in rodents receiving liraglutide. These proliferative changes included benign and malignant $\mathrm{C}$-cell neoplasia (eg, MTC) and were dose-dependent and treatment-durationdependent. ${ }^{92}$ Serum calcitonin is a biomarker of MTC. As a result of the findings in rodents, serum calcitonin levels were measured during clinical trials with liraglutide. At weeks 26 and 52 in clinical trials, adjusted mean serum calcitonin levels were higher in liraglutide-treated patients than placebo patients, but were not higher than patients receiving active comparator. There have been no clear-cut cases of MTC in patients treated with liraglutide. Liraglutide-treated patients who develop elevated serum calcitonin levels or thyroid nodules on physical examination or neck imaging should be referred to an endocrinologist for further evaluation..$^{92}$

Other GLP-1 receptor agonists in clinical development that have demonstrated glucose and weight-lowering effects 
include taspoglutide and albiglutide. Taspoglutide has been shown to reduce $\mathrm{HbA}_{1 \mathrm{c}}$ (up to $-1.2 \%$ ) and weight (up to $-2.8 \mathrm{~kg}$ ) when added to MET, ${ }^{102}$ and albiglutide reduced fasting plasma glucose (FPG) and postprandial concentrations in patients with type 2 diabetes. ${ }^{103}$

\section{DPP-IV inhibitors}

Sitagliptin is the first US FDA-approved DPP-IV inhibitor. It has been shown to stimulate glucose-dependent insulin secretion and inhibit glucagon secretion, as well as mitigate fasting and PPG concentrations and reduce elevated $\mathrm{HbA}_{1 \mathrm{c}}$. Treatment with orally administered sitagliptin has demonstrated efficacy with a once-daily dosage regimen. ${ }^{104}$ After 18 weeks of treatment in 521 patients with type 2 diabetes, $\mathrm{HbA}_{1 \mathrm{c}}$ was significantly reduced with sitagliptin (100 and $200 \mathrm{mg}$ ) compared with placebo (placebo-subtracted $\mathrm{HbA}_{1 \mathrm{c}}$ reduction, $-0.60 \%$ and $-0.48 \%$, respectively). Sitagliptin also improved FPG, HOMA-B, and fasting proinsulin:insulin ratio but had a neutral effect on body weight.

The incidence of hypoglycemia did not differ significantly between sitagliptin and placebo. ${ }^{105}$ In a 24-week study, the addition of sitagliptin to MET in 1,091 patients with type 2 diabetes was associated with placebo-subtracted $\mathrm{HbA}_{1 \mathrm{c}}$ changes from baseline up to $-2.07 \%(P<0.001$ for comparisons vs placebo and coadministration vs respective monotherapies). The incidence of hypoglycemia was low $(0.5 \%-2.2 \%)$ across active treatment groups and did not differ significantly from placebo $(0.6 \%){ }^{106}$

In another study of 441 patients, the addition of sitagliptin to glimepiride \pm MET reduced $\mathrm{HbA}_{1 \mathrm{c}}$ by $-0.74 \%(P<0.001)$ versus placebo after 24 weeks. The addition of sitagliptin reduced FPG by $-20.1 \mathrm{mg} / \mathrm{dL}(P<0.001)$ and increased HOMA-B by $12 \%(P<0.05)$ relative to placebo. Weight and incidences of hypoglycemia increased in the sitagliptin treatment group compared with placebo $(+0.8 \mathrm{vs}-0.4 \mathrm{~kg}$; $P<0.001$ and $12 \%$ vs $2 \%$, respectively). ${ }^{107}$

Saxagliptin is another DPP-IV inhibitor that has received US FDA approval. In addition to its glucose-lowering potential, saxagliptin may also have some cardioprotective effects. ${ }^{108}$ An analysis of 8 randomized, double-blind, phase IIb/III trials, involving 3,356 subjects randomized to saxagliptin and 1,251 subjects randomized to comparator, showed no increased CV risk with saxagliptin as monotherapy or in combination. The data raise the possibility of a cardioprotective effect that requires further study. ${ }^{108}$ Other DPP-IV inhibitors in clinical development include alogliptin ${ }^{109}$ and vildagliptin (which is currently available in the European Union and Latin America but has not been approved in the United States).
In clinical studies, DPP-IV inhibitors have been associated with improvements in BP, dyslipidemia, and inflammatory cytokine levels but have not been shown to accelerate weight loss in patients with type 2 diabetes. ${ }^{110-112}$ DPP-IV therapy has been associated with an increased incidence of upper respiratory infections, nasopharyngitis, and headache. Other rare, but more serious, adverse events include hypersensitivity reactions and anaphylaxis. ${ }^{10,113}$ Postmarketing surveillance shows that between October 16, 2006 and February 9, 2009, 88 cases of acute pancreatitis were reported to the US FDA in association with sitagliptin therapy, including 2 cases of hemorrhagic or necrotizing pancreatitis. The manufacturer has been asked to update their product labeling as a result of these spontaneous case reports. ${ }^{114}$

\section{GLP-I receptor agonists versus DPP-IV inhibitors}

The effects of exenatide and sitagliptin were compared in a 2-week study in which 61 patients with type 2 diabetes received $5 \mu \mathrm{g}$ BID of exenatide subcutaneously for 1 week, then $10 \mu \mathrm{g}$ for 1 week, or $100 \mathrm{mg}$ of oral sitagliptin every morning for 2 weeks. Patients crossed over to the alternate therapy after 2 weeks of treatment. Exenatide had a significantly greater effect in reducing 2-hour PPG concentration $(133 \mathrm{mg} / \mathrm{dL})$ than sitagliptin $(208 \mathrm{mg} / \mathrm{dL}, P<0.0001)$, although the effects of both agents in reducing FPG was similar. Exenatide also significantly improved the insulinogenic index of insulin secretion $(1.50, P=0.0239)$, reduced postprandial glucagon secretion $(0.88, P=0.0011)$, slowed gastric emptying $(0.56, P<0.0001)$, and reduced total caloric intake ( $-134 \mathrm{kcal}$ vs $+130 \mathrm{kcal}, P=0.0227)$ compared with sitagliptin. ${ }^{85}$ An additional comparative study is ongoing, which will provide more information to clinicians, who must select the right drug for the appropriate patient, matching drug and patient characteristics.

\section{Investigational incretin use perioperatively: CABG}

To reap the potential acute benefits of incretin use perioperatively as suggested by studies with GLP-1 used in surgery, ${ }^{61}$ including the possibility of avoiding the use of hypoglycemic agents postoperatively (especially in patients not previously known to have diabetes or only requiring prior oral therapy for diabetes preadmission), incretins have been used in surgery including CABG and openheart surgery (Table 2). Our experience at the University of Pennsylvania in $\sim 100$ patients has shown that sitagliptin is well tolerated and is equal to $\sim 20 \mathrm{U}$ of insulin, whereas 
Table 2 Perioperative glycemic guidelines used at the University of Pennsylvania

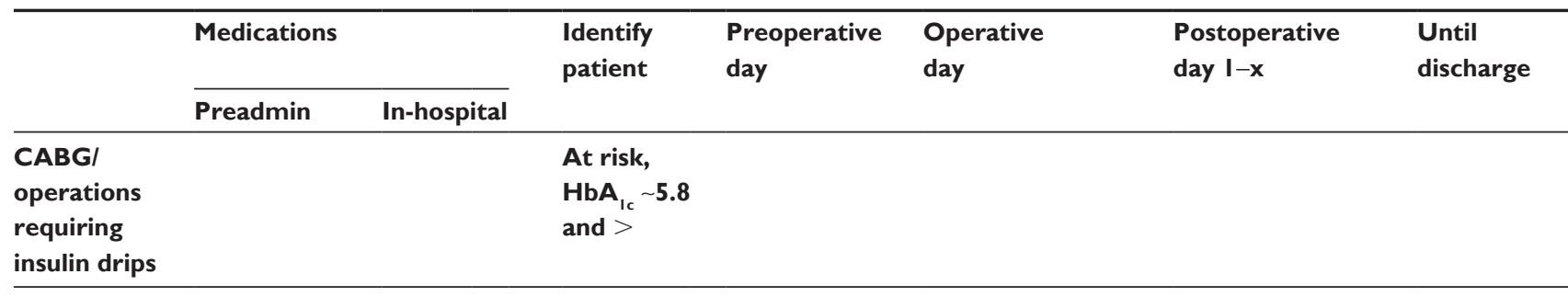

Non-diabetes

mellitus

\begin{tabular}{|c|c|c|c|c|c|c|}
\hline & & IV insulin drip & & $\sqrt{ }$ & $\sqrt{ }$ (until AM day 3 ) & \\
\hline & & Incretin ${ }^{a}$ & & & Start & $\sqrt{ }$ \\
\hline & & SFU/Pio/MET & & & & $\sqrt{ }$ \\
\hline & & as below & & & & \\
\hline & & CF fast-analog & & & $\sqrt{ }$ (when off drip) & $\sqrt{ }$ \\
\hline IFG/IGT/DM & & & & & & \\
\hline & Incretin ${ }^{a}$ & & $\sqrt{ }$ or start & $\sqrt{ }$ & $\sqrt{ }$ & $\sqrt{ }$ \\
\hline & SFU/glinide & & $\sqrt{ }$ & $x$ & $\mathrm{X}$ & Consider \\
\hline & $\mathrm{Pio}^{\mathrm{b}}$ & & $\sqrt{ }$ & & $\sqrt{ }$ & $\sqrt{ }$ \\
\hline & $\mathrm{MET}^{\mathrm{c}}$ & & $X$ & $X$ & $X$ & Only if stable \\
\hline & & IV insulin drip & & $\sqrt{ }$ & $\sqrt{ }$ (stop AM day 3$)$ & \\
\hline & Basal insulin & & & & & \\
\hline & Bolus insulin & & & & If normal PO- may & If normal PO \\
\hline & & & & & not need if on & \\
\hline & & & & & incretin & \\
\hline & & CF fast-analog & & & $\sqrt{ }$ (when off drip) & $\sqrt{ }$ \\
\hline Non-CABG & & & & & & \\
\hline Non-diabetes & & & & Postoperative & Postoperative blood & \\
\hline mellitus & & & & bloodglucose $>$ I 80 & glucose $>180$ & \\
\hline & & Incretin & & & Start & \\
\hline & & SFU/Pio/MET as & & & & $\sqrt{ }$ \\
\hline & & below & & & & \\
\hline & & CF aspart & & & $\sqrt{ }$ & $\sqrt{ }$ \\
\hline IFG/IGT/DM & & & & & & \\
\hline & Incretin $^{\mathrm{a}}$ & $\sqrt{ }$ or start & $\sqrt{ }$ & $\sqrt{ }$ & $\sqrt{ }$ & $\sqrt{ }$ \\
\hline & SFU/glinide & & $\sqrt{ }$ & $x$ & $X$ & Consider \\
\hline & $\mathrm{Pio}^{\mathrm{b}}$ & & $\sqrt{ }$ & $x$ & $\sqrt{ }$ & $\sqrt{ }$ \\
\hline & $\mathrm{MET}^{c}$ & & $x$ & $x$ & $\mathrm{X}$ & Only if stable \\
\hline & Basal insulin & & $\sqrt{ }$ & $\sqrt{ }$ & $\sqrt{ }$ & $\sqrt{ }$ \\
\hline & Bolus insulin & & If normal meals & & If normal PO-may & If normal \\
\hline & & & & & not need if on & meals \\
\hline & & & & & incretin & \\
\hline & CF fast-analog & & & & $\sqrt{ }$ & $\sqrt{ }$ \\
\hline
\end{tabular}

Notes: ancretin administration: exenatide may be administered when patient is either NPO or PO (when operative-associated nausea is gone). DPP-IV inhibitors administered only when patient is PO. 'P Pioglitazone can only be administered if the patient does not have a history of congestive heart failure. ${ }^{\mathrm{C}}$ Metformin $\mathrm{Cr}<\mathrm{I} .5$ male, $<$ I.4 female, age $<70$ years.

Abbreviations: CABG, coronary artery bypass graft; HbA ${ }_{1 \mathrm{c}}$, glycated hemoglobin; IV, intravenous; SFU, sulfonylurea/glinide; Pio, pioglitazone; MET, metformin; CF, correction factor; IFG, impaired fasting glucose; IGT, impaired glucose tolerance; DM, diabetes mellitus; PO, per oral; DPP-IV, dipeptidyl peptidase-IV inhibitor; NPO, nothing by mouth; $X$, not given; $\sqrt{ }$, given.

exenatide is equal to $\sim 40 \mathrm{U}$ of insulin. According to a written communication from G. Umpierrez (January 13, 2010), when one stops insulin drips on day 3 using post-CABG insulin drip protocols, most patients with drip rates $<2.5$ $\mathrm{U} / \mathrm{h}$ for the last 6 hours do quite well with sitagliptin alone. Though there has been some concern about perioperative nausea with exenatide, this has occurred infrequently since only $\sim 1 \%$ of patients have a hypothalamic super sensitivity to the agent. Clinically reported nausea is predominantly related to eating after feeling "full." As most patients have less food intake following surgery, nausea after surgery has not been a significant issue. 


\section{Conclusion}

Current guidelines from the ADA advocate SFU use early in the diabetes disease process. The ADA only recommends GLP-1 receptor agonists (eg, exenatide) if there are concerns about the development of hypoglycemia or weight gain. Given the detrimental effects of these variables on CVD and further glycemic control, it seems very prudent to take these factors into account when considering antidiabetes agents. Thus, guidelines that avoid the use of oral antidiabetes agents associated with hypoglycemia and weight gain (eg, AACE/ACE algorithm) are more logical and becoming increasingly popular in treating patients with diabetes, even perioperatively.

Type 2 diabetes and CVD share many pathophysiologic nuances as they continue to grow at epidemic rates. Since these conditions are interrelated, optimized treatment strategies for patients with type 2 diabetes should not only focus solely on hyperglycemia but also address other CVD risk factors, including overweight/obesity, elevated BP, and dyslipidemia. The results of studies such as Steno-2 highlight the importance of controlling all $\mathrm{CV}$ risk factors in patients with type 2 diabetes. The confusing results from outcome studies that examined these variables in patients with type 2 diabetes, such as ACCORD, ADVANCE, and NICESUGAR, may be secondary to the use of nonideal hypoglycemic agents (eg, SFUs in ADVANCE). Moreover, therapies that increase hypoglycemia and weight (ACCORD) and thus suggest increased fatal MIs should not lead to glycemic therapeutic nihilism. As vascular damage accrues early in the type 2 diabetes disease process and is directly related to the abnormal metabolic environment/hyperglycemia, the addition of incretin-based therapies to the antidiabetes agent armamentarium offers strong potential for treatments that work on the underlying defects of type 2 diabetes by decreasing glycemic levels without hypoglycemia, and while reducing weight and $\mathrm{CV}$ risk factors. Clinical data continues to accumulate supporting the use of incretinbased therapies as optimal therapy for glucose lowering, as well as for reducing the risk of CVD-related morbidity and mortality, although more data, particularly on CV outcomes, is required.

\section{Acknowledgment}

The authors thank Jonathan Wert, MD of BlueSpark Healthcare Communications, for providing literature research and editorial assistance, made possible through funding from Amylin Pharmaceutical, Inc and Eli Lilly and Company.

\section{Disclosure}

Dr Schwartz participates in the Speakers Bureaus for Eli Lilly and Company, Merck and Co., Inc, Novo Nordisk Inc, sanofi-aventis US, Takeda Pharmaceuticals North America, Inc, Bristol-Myers Squibb Company, AstraZeneca, Amylin Pharmaceuticals, Inc, and Advisory Boards for Gilead Sciences, Inc., Eli Lilly and Company, Merck and Co., Inc, Novo Nordisk Inc, Takeda Pharmaceuticals North America, Inc, Amylin Pharmaceuticals, Inc, and Medtronic. Dr Kohl has received funding from Amylin Pharmaceuticals, Inc.

\section{References}

1. Brownlee M. Biochemistry and molecular cell biology of diabetic complications. Nature. 2001;414(6865):813-820.

2. Brunner EJ, Shipley MJ, Witte DR, Fuller JH, Marmot MG. Relation between blood glucose and coronary mortality over 33 years in the Whitehall Study. Diabetes Care. 2006;29(1):26-31.

3. DECODE Study Group. European Diabetes Epidemiology Group. Diabetes Epidemiology: Collaborative analysis Of Diagnostic criteria in Europe (DECODE). Glucose tolerance and mortality: comparison of WHO and American Diabetes Association diagnostic criteria. Lancet. 1999;354(9179):617-621.

4. Sattar N, Gaw A, Scherbakova O, et al. Metabolic syndrome with and without $\mathrm{C}$-reactive protein as a predictor of coronary heart disease and diabetes in the West of Scotland Coronary Prevention Study. Circulation. 2003;108(4):414-419.

5. Stratton IM, Adler AI, Neil HA, et al. Association of glycaemia with macrovascular and microvascular complications of type 2 diabetes (UKPDS 35): prospective observational study. BMJ. 2000; 321(7258):405-412.

6. Diabetes Control and Complications Trial (DCCT) Research Group. The effect of intensive treatment of diabetes on the development and progression of long-term complications in insulin-dependent diabetes mellitus. N Engl J Med. 1993;329(14):977-986.

7. Hanley AJ, Williams K, Stern MP, Haffner SM. Homeostasis model assessment of insulin resistance in relation to the incidence of cardiovascular disease: the San Antonio Heart Study. Diabetes Care. 2002; 25(7):1177-1184.

8. Yusuf S, Sleight P, Pogue J, Bosch J, Davies R, Dagenais G Effects of an angiotensin-converting-enzyme inhibitor, ramipril, on cardiovascular events in high-risk patients. The Heart Outcomes Prevention Evaluation Study Investigators. $N$ Engl J Med. 2000;342(3):145-153.

9. Dagenais GR, Yi Q, Mann JF, Bosch J, Pogue J, Yusuf S. Prognostic impact of body weight and abdominal obesity in women and men with cardiovascular disease. Am Heart J. 2005;149(1):54-60.

10. Smith NL, Barzilay JI, Shaffer D, et al. Fasting and 2-hour postchallenge serum glucose measures and risk of incident cardiovascular events in the elderly: the Cardiovascular Health Study. Arch Intern Med. 2002;162(2):209-216.

11. Hu FB, Stampfer MJ, Haffner SM, Solomon CG, Willett WC, Manson JE. Elevated risk of cardiovascular disease prior to clinical diagnosis of type 2 diabetes. Diabetes Care. 2002;25(7):1129-1134.

12. Khaw KT, Wareham N, Bingham S, Luben R, Welch A, Day N. Association of hemoglobin A1c with cardiovascular disease and mortality in adults: the European prospective investigation into cancer in Norfolk Ann Intern Med. 2004;141(6):413-420.

13. Haffner SM, Lehto S, Rönnemaa T, Pyörälä K, Laakso M. Mortality from coronary heart disease in subjects with type 2 diabetes and in nondiabetic subjects with and without prior myocardial infarction. N Engl J Med. 1998;339(4):229-234. 
14. Gæde P, Lund-Andersen H, Parving HH, Pedersen O. Effect of a multifactorial intervention on mortality in type 2 diabetes. $N$ Engl $J$ Med. 2008;358(6):580-591.

15. Capes SE, Hunt D, Malmberg K, Gerstein HC. Stress hyperglycaemia and increased risk of death after myocardial infarction in patients with and without diabetes: a systematic overview. Lancet. 2000;355(9206):773-778.

16. Muhlestein JB, Anderson JL, Horne BD, et al; for the Intermountain Heart Collaborative Study Group. Effect of fasting glucose levels on mortality rate in patients with and without diabetes mellitus and coronary artery disease undergoing percutaneous coronary intervention. Am Heart J. 2003;146(2):351-358.

17. Norhammar A, Tenerz A, Nilsson G, et al. Glucose metabolism in patients with acute myocardial infarction and no previous diagnosis of diabetes mellitus: a prospective study. Lancet. 2002;359(9324): 2140-2144.

18. Kosiborod M, Inzucchi SE, Krumholz HM, et al. Glucose normalization and outcomes in patients with acute myocardial infarction. Arch Intern Med. 2009;169(5):438-446.

19. Finfer S, Chittock DR, Su SY, et al; for NICE-SUGAR Study Investigators. Intensive versus conventional glucose control in critically ill patients. N Engl J Med. 2009;360(13):1283-1297.

20. Inzucchi SE, Siegel MD. Glucose control in the ICU - how tight is too tight? N Engl J Med. 2009;360(13):1346-1349.

21. United Kingdom Prospective Diabetes Study (UKPDS) Group. Intensive blood-glucose control with sulphonylureas or insulin compared with conventional treatment and risk of complications in patients with type 2 diabetes (UKPDS 33). Lancet. 1998;352(9131): 837-853.

22. Skyler JS, Bergenstal R, Bonow RO, et al. Intensive glycemic control and the prevention of cardiovascular events: implications of the ACCORD, ADVANCE, and VA diabetes trials: a position statement of the American Diabetes Association and a scientific statement of the American College of Cardiology Foundation and the American Heart Association. Diabetes Care. 2009;32(1):187-192.

23. Holman RR, Paul SK, Bethel MA, Matthews DR, Neil HA. 10-year follow-up of intensive glucose control in type 2 diabetes. $N$ Engl $J$ Med. 2008;359(15):1577-1589.

24. Duckworth W, Abraira C, Moritz T, et al. Glucose control and vascular complications in veterans with type 2 diabetes. $N$ Engl J Med. 2009;360(2):129-139.

25. Patel A, MacMahon S, Chalmers J, et al; for the Action in Diabetes and Vascular Disease: Preterax and Diamicron Modified Release and Controlled Evaluation (ADVANCE) Collaborative Group. Intensive blood glucose control and vascular outcomes in patients with type 2 diabetes. N Engl J Med. 2008;358(24):2560-2572.

26. Gerstein HC, Miller ME, Byington RP, et al; for the Action to Control Cardiovascular Risk in Diabetes (ACCORD) Study Group. Effects of intensive glucose lowering in type 2 diabetes. $N$ Engl J Med. 2008;358(24):2545-2559.

27. Ray KK, Seshasai SR, Wijesuriya S, et al. Effect of intensive control of glucose on cardiovascular outcomes and death in patients with diabetes mellitus: a meta-analysis of randomised controlled trials. Lancet. 2009;373(9677):1765-1772.

28. Mannucci E, Monami M, Lamanna C, Gori F, Marchionni N. Prevention of cardiovascular disease through glycemic control in type 2 diabetes: a meta-analysis of randomized clinical trials. Nutr Metab Cardiovasc Dis. 2009;19(9):604-612.

29. Currie CJ, Peters JR, Tynan A, et al. Survival as a function of $\mathrm{HbA}_{1 \mathrm{c}}$ in people with type 2 diabetes: a retrospective cohort study. Lancet. 2010;375(9713):481-489.

30. del Prato S. Megatrials in type 2 diabetes. From excitement to frustration? Diabetologia. 2009;52(7):1219-1226.

31. Rodbard HW, Jellinger PS, Davidson JA, et al. Statement by an American Association of Clinical Endocrinologists/American College of Endocrinology consensus panel on type 2 diabetes mellitus: an algorithm for glycemic control. Endocr Pract. 2009;15(6): $540-559$.
32. Haffner SM. Relationship of metabolic risk factors and development of cardiovascular disease and diabetes. Obesity (Silver Spring). 2006;14 Suppl 3:S121-S127.

33. DeFronzo RA. Banting Lecture. From the triumvirate to the ominous octet: a new paradigm for the treatment of type 2 diabetes mellitus. Diabetes. 2009;58(4):773-795.

34. Nathan DM, Buse JB, Davidson MB, et al. Medical management of hyperglycemia in type 2 diabetes: a consensus algorithm for the initiation and adjustment of therapy. Diabetes Care. 2009;32(1):193-203.

35. Wajchenberg BL. Beta-cell failure in diabetes and preservation by clinical treatment. Endocr Rev. 2007;28(2):187-218.

36. Rao AD, Kuhadiya N, Reynolds K, Fonseca VA. Is the combination of sulfonylureas and metformin associated with an increased risk of cardiovascular disease or all-cause mortality? A metaanalysis of observational studies. Diabetes Care. 2008;31(8): 1672-1678.

37. Nauck MA, Homberger E, Siegel EG, et al. Incretin effects of increasing glucose loads in man calculated from venous insulin and C-peptide responses. J Clin Endocrinol Metab. 1986;63(2): 492-498.

38. Nauck MA. Unraveling the science of incretin biology. Am J Med. 2009;122 Suppl 6:S3-S10.

39. Girard J. The incretins: from the concept to their use in the treatment of type 2 diabetes. Part A: incretins: concept and physiological functions. Diabetes Metab. 2008;34(6 Pt 1):550-559.

40. Drucker DJ. The biology of incretin hormones. Cell Metab. 2006;3(3): 153-165.

41. Toft-Nielsen MB, Damholt MB, Madsbad S, et al. Determinants of the impaired secretion of glucagon-like peptide- 1 in type 2 diabetic patients. J Clin Endocrinol Metab. 2001;86(8):3717-3723.

42. Vilsbøll T, Knop FK, Krarup T, et al. The pathophysiology of diabetes involves a defective amplification of the late-phase insulin response to glucose by glucose-dependent insulinotropic polypeptideregardless of etiology and phenotype. J Clin Endocrinol Metab. 2003;88(10):4897-4903.

43. Zander M, Madsbad S, Madsen JL, Holst JJ. Effect of 6-week course of glucagon-like peptide 1 on glycaemic control, insulin sensitivity, and beta-cell function in type 2 diabetes: a parallel-group study. Lancet. 2002;359(9309):824-830.

44. Rachman J, Barrow BA, Levy JC, Turner RC. Near-normalisation of diurnal glucose concentrations by continuous administration of glucagon-like peptide-1 (GLP-1) in subjects with NIDDM. Diabetologia. 1997;40(2):205-211.

45. Nauck MA, Kleine N, Orskov C, Holst JJ, Willms B, Creutzfeldt W. Normalization of fasting hyperglycaemia by exogenous glucagon-like peptide 1 (7-36 amide) in type 2 (non-insulin-dependent) diabetic patients. Diabetologia. 1993;36(8):741-744.

46. Hinke SA, Hellemans K, Schuit F. Plasticity of the $\beta$ cell insulin secretory competence: preparing the pancreatic $\beta$ cell for the next meal. J Physiol. 2004;558(Pt 2):369-380.

47. Henquin JC. Triggering and amplifying pathways of regulation of insulin secretion by glucose. Diabetes. 2000;49(11):1751-1760.

48. Henquin JC. Pathways in $\beta$-cell stimulus-secretion coupling as targets for therapeutic insulin secretagogues. Diabetes. 2004;53 Suppl 3: S48-S58.

49. Gillison S, Bartlett ST, Curry D. Inhibition by cyclosporine of insulin secretion $-\mathrm{a} \beta$ cell-specific alteration of islet tissue function. Transplantation. 1991;52(5):890-895.

50. Van Raalte DH, Ouwens DM, Diamant M. Novel insights into glucocorticoid-meidated diabetogenic effects: towards expansion of therapeutic options? Eur J Clin Invest. 2009;39(2): 81-93.

51. Drucker DJ. Glucagon-like peptide-1 and the islet beta-cell: augmentation of cell proliferation and inhibition of apoptosis. Endocrinology. 2003;144(12):5145-5148.

52. Ritzel RA. Therapeutic approaches based on beta-cell mass preservation and/or regeneration. Front Biosci. 2009;14:1835-1850. 
53. Li Y, Cao X, Li LX, Brubaker PL, Edlund H, Drucker DJ. Beta-cell $\mathrm{Pdx} 1$ expression is essential for the glucoregulatory, proliferative, and cytoprotective actions of glucagon-like peptide-1. Diabetes. 2005;54(2): 482-491.

54. Ranta F, Avram D, Berchtold S, et al. Dexamethasone induces cell death in insulin-secreting cells, an effect reversed by exendin- 4 . Diabetes. 2006;55(5):1380-1390.

55. D’Amico E, Hui H, Khoury N, Di Mario U, Perfetti R. Pancreatic beta-cells expressing GLP-1 are resistant to the toxic effects of immunosuppressive drugs. J Mol Endocrinol. 2005;34(2):377-390.

56. Lambillotte C, Gilon P, Henquin JC. Direct glucocorticoid inhibition of insulin secretion. An in vitro study of dexamethasone effects in mouse islets. J Clin Invest. 1997;99(3):414-423.

57. Meier JJ, Weyhe D, Michaely M, et al. Intravenous glucagon-like peptide 1 normalizes blood glucose after major surgery in patients with type 2 diabetes. Crit Care Med. 2004;32(3):848-851.

58. Bunck MC, Diamant M, Corner A, et al. One-year treatment with exenatide improves $\beta$-cell function, compared with insulin glargine, in metformin-treated type 2 diabetic patients. Diabetes Care 2009;32(5):762-768.

59. Klonoff DC, Buse JB, Nielsen LL, et al. Exenatide effects on diabetes, obesity, cardiovascular risk factors and hepatic biomarkers in patients with type 2 diabetes treated for at least 3 years. Curr Med Res Opin. 2008;24(1):275-286.

60. Schwartz S. TZDs in combination with incretins: synergy in diabetes treatment. Rev Endocrinol. 2008;11:37-44.

61. Kohl BA, Schwartz S. Surgery in the patient with endocrine dysfunction. Med Clin North Am. 2009;93(5):1031-1047.

62. Ban K, Noyan-Ashraf MH, Hoefer J, et al. Cardioprotective and vasodilatory actions of glucagon-like peptide 1 receptor are mediated through both glucagon-like peptide 1 receptor-dependent and -independent pathways. Circulation. 2008;117(18):2340-2350.

63. Sulistio M, Carothers C, Mangat M, Lujan M, Oliveros R, Chilton R. GLP-1 agonist-based therapies: an emerging new class of antidiabetic drug with potential cardioprotective effects. Curr Atheroscler Rep. 2009;11(2):93-99.

64. Nyström T, Gonon AT, Sjöholm A, Pernow J. Glucagon-like peptide-1 relaxes rat conduit arteries via an endothelium-independent mechanism. Regul Pept. 2005;125(1-3):173-177.

65. Nikolaidis LA, Mankad S, Sokos GG, et al. Effects of glucagonlike peptide-1 in patients with acute myocardial infarction and left ventricular dysfunction after successful reperfusion. Circulation. 2004;109(8):962-965.

66. Sokos GG, Nikolaidis LA, Mankad S, Elahi D, Shannon RP. Glucagonlike peptide-1 infusion improves left ventricular ejection fraction and functional status in patients with chronic heart failure. J Card Fail. 2006;12(9):694-699.

67. Sokos GG, Bolukoglu H, German J, et al. Effect of glucagon-like peptide-1 (GLP-1) on glycemic control and left ventricular function in patients undergoing coronary artery bypass grafting. $J$ Cardiol. 2007;100(5):824-829.

68. Kim W, Egan JM. The role of incretins in glucose homeostasis and diabetes treatment. Pharmacol Rev. 2008;60(4):470-512.

69. Eng J, Kleinman WA, Singh L, Singh G, Raufman JP. Isolation and characterization of exendin-4, an exendin-3 analogue, from Heloderma suspectum venom. Further evidence for an exendin receptor on dispersed acini from guinea pig pancreas. J Biol Chem. 1992;267(11):7402-7405.

70. Byetta [package insert]. San Diego, CA: Amylin Pharmaceuticals, Inc; 2009.

71. Buse JB, Henry RR, Han J, Kim DD, Fineman MS, Baron AD; for the Exenatide-113 Clinical Study Group. Effects of exenatide (exendin-4) on glycemic control over 30 weeks in sulfonylureatreated patients with type 2 diabetes. Diabetes Care. 2004;27(11): 2628-2635.

72. DeFronzo RA, Ratner RE, Han J, Kim DD, Fineman MS, Baron AD. Effects of exenatide (exendin-4) on glycemic control and weight over 30 weeks in metformin-treated patients with type 2 diabetes. Diabetes Care. 2005;28(5):1092-1100.
73. Kendall DM, Riddle MC, Rosenstock J, et al. Effects of exenatide (exendin-4) on glycemic control over 30 weeks in patients with type 2 diabetes treated with metformin and a sulfonylurea. Diabetes Care. 2005;28(5):1083-1091.

74. Blonde L, Klein EJ, Han J, et al. Interim analysis of the effects of exenatide treatment on $\mathrm{A} 1 \mathrm{C}$, weight and cardiovascular risk factors over 82 weeks in 314 overweight patients with type 2 diabetes. Diabetes Obes Metab. 2006;8(4):436-447.

75. Heine RJ, Van Gaal LF, Johns D, Mihm MJ, Widel MH, Brodows RG. Exenatide versus insulin glargine in patients with suboptimally controlled type 2 diabetes: a randomized trial. Ann Intern Med. 2005;143(8):559-569.

76. Nauck MA, Duran S, Kim D, et al. A comparison of twice-daily exenatide and biphasic insulin aspart in patients with type 2 diabetes who were suboptimally controlled with sulfonylurea and metformin: a non-inferiority study. Diabetologia. 2007;50(2):259-267.

77. Barnett AH, Burger J, Johns D, et al. Tolerability and efficacy of exenatide and titrated insulin glargine in adult patients with type 2 diabetes previously uncontrolled with metformin or a sulfonylurea: a multinational, randomized, open-label, two-period, crossover noninferiority trial. Clin Ther. 2007;29(11):2333-2348.

78. Bhushan R, Elkind-Hirsch KE, Bhushan M, Butler WJ, Duncan K, Marrioneaux $\mathrm{O}$. Exenatide use in the management of metabolic syndrome: a retrospective database study. Endocr Pract. 2008;14(8):993-999.

79. Bunck MC, Corner A, Eliasson B, et al. One year exenatide therapy, compared with insulin glargine, reduces postprandial oxidative stress in metformin-treated patients with type 2 diabetes. Diabetes. 2009;58 Suppl 1:A147 [Abstract 548-P].

80. Bunck MC, Diamant M, Eliasson B, et al. Beneficial changes on body composition and circulating adiponectin and hsCRP levels following one year of exenatide therapy, compared with insulin glargine, in metformin-treated patients with type 2 diabetes. Diabetes. 2009;58 Suppl 1:A125 [Abstract 469-P].

81. Gentilella R, Bianchi C, Rossi A, Rotella CM. Exenatide: a review from pharmacology to clinical practice. Diabetes Obes Metab. 2009;11(6): 544-556.

82. Shen L, Han J, Yushmanova I, Bruce S, Porter L. Cardiovascular safety of exenatide BID: an integrated analysis from long-term controlled clinical trials in subjects with type 2 diabetes. Diabetes. 2009;58 Suppl 1:A96-A97 [Abstract 366-OR].

83. Best JH, Herman WH, Wintle M. Estimating the potential cardiovascular benefit of A1c reduction and weight loss in patients with type 2 diabetes treated with exenatide for at least 3 years. Diabetes. 2009;58 Suppl 1:A316 [Abstract 1202-P].

84. Fineman MS, Shen LZ, Taylor K, Baron AD. Effectiveness of progressive dose-escalation of exenatide (exendin-4) in reducing doselimiting effects in subjects with type 2 diabetes. Diabetes Metab Res Rev. 2004;20(5):411-417.

85. DeFronzo RA, Okerson T, Viswanathan P, Guan X, Holcombe JH, MacConell L. Effects of exenatide versus sitagliptin on postprandial glucose, insulin and glucagon secretion, gastric emptying, and caloric intake: a randomized, cross-over study. Curr Med Res Opin. 2008;24(10):2943-2952.

86. Bruce S, MacConell L, Brown C, et al. Safety and tolerability of exenatide BID in patients with type 2 diabetes: integrated analysis of 3854 patients from 11 comparator controlled clinical trials. Diabetes. 2009;58 Suppl 1:A155-A156 [Abstract 578-P].

87. Bloomgren G, Dore D, Patterson R, Noel R, Braun D, Seeger J. Incidence of acute pancreatitis in exenatide initiators compared to other antidiabetic drug initiators: a retrospective, cohort study. Diabetes. 2009;58 Suppl 1:A41 [Abstract 158-OR].

88. Bergenstal RM, Kim T, Trautmann M, Zhuang D, Okerson T, Taylor K. Exenatide once weekly elicited improvements in blood pressure and lipid profile over 52 weeks in patients with type 2 diabetes. Circulation. 2008;118 Suppl 1:1086 [Abstract 1239].

89. Drucker DJ, Buse JB, Taylor K, et al; for the DURATION-1 Study Group. Exenatide once weekly versus twice daily for the treatment of type 2 diabetes: a randomised, open-label, non-inferiority study. Lancet. 2008;372(9645):1240-1250. 
90. Nauck M, Frid A, Hermansen K, et al; for the LEAD-2 Study Group. Efficacy and safety comparison of liraglutide, glimepiride, and placebo, all in combination with metformin, in type 2 diabetes: the LEAD (Liraglutide Effect and Action in Diabetes)-2 study. Diabetes Care. 2009;32(1):84-90.

91. Russell-Jones D. Molecular, pharmacological and clinical aspects of liraglutide, a once-daily human GLP-1 analogue. Mol Cell Endocrinol. 2009;297(1-2):137-140.

92. Victoza (liraglutide) [package insert]. Princeton, NJ: Novo Nordisk Inc; 2010.

93. Garber A, Henry R, Ratner R, et al; for the LEAD-3 Mono Study Group. Liraglutide versus glimepiride monotherapy for type 2 diabetes (LEAD-3 Mono): a randomised, 52-week, phase III, double-blind, parallel-treatment trial. Lancet. 2009;373(9662):473-481.

94. Madsbad S. Liraglutide effect and action in diabetes (LEAD) trial. Expert Rev Endocrinol Metab. 2009;4(2):119-129.

95. Marre M, Shaw J, Brändle M, et al; for the LEAD-1 SU Study Group. Liraglutide, a once-daily human GLP-1 analogue, added to a sulphonylurea over 26 weeks produces greater improvements in glycaemic and weight control compared with adding rosiglitazone or placebo in subjects with Type 2 diabetes (LEAD-1 SU). Diabet Med. 2009;26(3):268-278.

96. Zinman B, Gerich J, Buse JB, et al; for the LEAD-4 Study Investigators. Efficacy and safety of the human GLP-1 analog liraglutide in combination with metformin and TZD in patients with type 2 diabetes mellitus (LEAD-4 Met+TZD). Diabetes Care. 2009;32(7):1224-1230.

97. Buse JB, Rosenstock J, Sesti G, et al; for the LEAD-6 Study Group. Liraglutide once a day versus exenatide twice a day for type 2 diabetes: a 26-week randomised, parallel-group, multinational, open-label trial (LEAD-6). Lancet. 2009;374(9683):39-47.

98. Courrèges JP, Vilsbøll T, Zdravkovic M, et al. Beneficial effects of once-daily liraglutide, a human glucagon-like peptide-1 analogue, on cardiovascular risk biomarkers in patients with type 2 diabetes. Diabet Med. 2008;25(9):1129-1131.

99. Sullivan SD, Alfonso-Cristancho R, Conner C, Hammer M, Blonde L. Improvement in cardiovascular risk factors and long-term outcomes in people with T2D treated with liraglutide or glimepiride monotherapy. Diabetes. 2009;58 Suppl 1:A595 [Abstract 2308-PO].

100. Zinman B, Buse J, Falahati A, Moses A, Gough S. Liraglutide more effectively achieves a composite endpoint for A1C, SBP and weight change than other diabetes therapies. Diabetes. 2009;58 Suppl 1:A143-A144 [Abstract 537-P].

101. Fonseca V, Madsbad S, Falahati A, Zychma MJ, Plutzky J. Oncedaily human GLP-1 analog liraglutide reduces systolic BP - a metaanalysis of six clinical trials (LEAD). Diabetes. 2009;58 Suppl 1:A146 [Abstract 545-P].

102. Nauck MA, Ratner RE, Kapitza C, Berria R, Boldrin M, Balena R. Treatment with the human once-weekly GLP-1 analogue taspoglutide in combination with metformin improves glycemic control and lowers body weight in patients with type 2 diabetes mellitus inadequately controlled with metformin alone: a double-blind placebo-controlled study. Diabetes Care. 2009;32(7):1237-1243.
103. Matthews JE, Stewart MW, De Boever EH, et al; for the Albiglutide Study Group. Pharmacodynamics, pharmacokinetics, safety, and tolerability of albiglutide, a long-acting glucagon-like peptide-1 mimetic, in patients with type 2 diabetes. J Clin Endocrinol Metab. 2008;93(12):4810-4817.

104. Herman GA, Stevens C, Van Dyck K, et al. Pharmacokinetics and pharmacodynamics of sitagliptin, an inhibitor of dipeptidyl peptidase IV, in healthy subjects: results from two randomized, double-blind, placebo-controlled studies with single oral doses. Clin Pharmacol Ther. 2005;78(6):675-688.

105. Raz I, Hanefeld M, Xu L, Caria C, Williams-Herman D, Khatami H; for the Sitagliptin Study 023 Group. Efficacy and safety of the dipeptidyl peptidase-4 inhibitor sitagliptin as monotherapy in patients with type 2 diabetes mellitus. Diabetologia. 2006;49(11):2564-2571.

106. Goldstein BJ, Feinglos MN, Lunceford JK, Johnson J, WilliamsHerman DE; for the Sitagliptin 036 Study Group. Effect of initial combination therapy with sitagliptin, a dipeptidyl peptidase- 4 inhibitor, and metformin on glycemic control in patients with type 2 diabetes. Diabetes Care. 2007;30(8):1979-1987.

107. Hermansen K, Kipnes M, Luo E, Fanurik D, Khatami H, Stein P; for the Sitagliptin Study 035 Group. Efficacy and safety of the dipeptidyl peptidase-4 inhibitor, sitagliptin, in patients with type 2 diabetes mellitus inadequately controlled on glimepiride alone or on glimepiride and metformin. Diabetes Obes Metab. 2007;9(5):733-745.

108. Wolf R, Frederich R, Fiedorek F, et al. Evaluation of CV risk in the saxagliptin clinical trials. Presented at the American Diabetes Association, 69th scientific sessions; 2009 June 5-9; New Orleans, LA:LB3 [Abstract 8-LB]. Available from: http://professional.diabetes. org/UserFiles/File/Scientific\%20Sessions/2009/Abstracts/LB\%20 Abstracts/09\%20ADA\%20-\%20Late\%20Breaking\%20Handout(1). pdf. Accessed Jan 12, 2010.

109. DeFronzo RA, Fleck PR, Wilson CA, Mekki Q; for the Alogliptin Study 010 Group. Efficacy and safety of the dipeptidyl peptidase-4 inhibitor alogliptin in patients with type 2 diabetes and inadequate glycemic control: a randomized, double-blind, placebo-controlled study. Diabetes Care. 2008;31(12):2315-2317.

110. Amori RE, Lau J, Pittas AG. Efficacy and safety of incretin therapy in type 2 diabetes: systematic review and meta-analysis. JAMA. 2007;298(2):194-206

111. Campbell RK, White JR Jr. More choices than ever before: emerging therapies for type 2 diabetes. Diabetes Educ. 2008;34(3):518-534.

112. McIntosh CH. Dipeptidyl peptidase IV inhibitors and diabetes therapy. Front Biosci. 2008;13:1753-1773.

113. Williams-Herman D, Round E, Swern AS, et al. Safety and tolerability of sitagliptin in patients with type 2 diabetes: a pooled analysis. $B M C$ Endocr Disord. 2008;8:14.

114. US Food and Drug Administration. Information for healthcare professionals - acute pancreatitis and sitagliptin (marketed as Januvia and Janumet). 2009 Sep 25. Available from: http://www.fda.gov/Drugs/ DrugSafety/PostmarketDrugSafetyInformationforPatientsandProviders/ DrugSafetyInformationforHeathcareProfessionals/ucm183764.htm. Accessed March 17, 2010.

\section{Publish your work in this journal}

Diabetes, Metabolic Syndrome and Obesity: Targets and Therapy is an international, peer-reviewed open-access journal committed to the rapid publication of the latest laboratory and clinical findings in the fields of diabetes, metabolic syndrome and obesity research. Original research, review, case reports, hypothesis formation, expert opinion and commentaries are all considered for publication. The manuscript management system is completely online and includes a very quick and fair peer-review system, which is all easy to use. Visit http://www.dovepress.com/testimonials.php to read real quotes from published authors. 